\title{
Impulsive actions and choices in laboratory animals and humans: effects of high vs. low dopamine states produced by systemic treatments given to neurologically intact subjects
}

\author{
Valérie D'Amour-Horvat ${ }^{1}$ and Marco Leyton ${ }^{1,2,3}$ * \\ ${ }^{1}$ Department of Psychology, McGill University, Montreal, OC, Canada \\ ${ }^{2}$ Department of Psychiatry, McGill University, Montreal, QC, Canada \\ ${ }^{3}$ Center for Studies in Behavioral Neurobiology, Concordia University, Montreal, OC, Canada
}

\section{Edited by:}

Jozsef Haller, Institute of

Experimental Medicine, Hungary

Reviewed by:

Christelle Baunez, Centre National de la Recherche Scientifique, France Juan Dominguez, University of

Texas at Austin, USA

*Correspondence:

Marco Leyton, Department of Psychiatry, McGill University,

Ludmer Research and Training

Building, 1033 Pine Avenue West,

Room 209, Montreal, H3A 1A1, OC,

Canada

e-mail:marco.leyton@mcgill.ca
Increases and decreases in dopamine (DA) transmission have both been suggested to influence reward-related impulse-control. The present literature review suggests that, in laboratory animals, the systemic administration of DA augmenters preferentially increases susceptibility to premature responding; with continued DA transmission, reward approach behaviors are sustained. Decreases in DA transmission, in comparison, diminish the appeal of distal and difficult to obtain rewards, thereby increasing susceptibility to temporal discounting and other forms of impulsive choice. The evidence available in humans is not incompatible with this model but is less extensive.

Keywords: impulsivity, compulsivity, addiction, gambling, motivation

\section{OVERVIEW}

Both low and high dopamine (DA) states have been proposed to affect impulse-control. These contrasting views might reflect different roles in different types of impulsivity. To address this possibility, we conducted literature searches using PubMed and Google Scholar, effective to October 20, 2014. The following terms were entered: impulsive action, stop signal, go/no-go, premature respon*, five-choice serial reaction time task (5-CSRT), differential reinforcement of low rates (DRL) of responding, simple reaction time task, conditional reaction time, impulsive choice, delay discount*, temporal discount*, effort discount*, probability discount*, Iowa Gambling, gambling, and decisionmaking, each entered separately in combination with dopamine, dopamine agonist, and dopamine antagonist. Papers were then selected for suitability with a focus on studies conducted with neurologically intact subjects following acute pharmacological challenges administered systemically. Although this focus ignores regionally specific effects within the brain, it identifies research with greater immediate clinical relevance with respect to the routes of drug and medication administration in humans. The strategy was supplemented by additional publications noted in the reference lists, and yielded a total of 88 papers. Overall, the reviewed evidence suggests that, in laboratory rodents, elevated DA transmission increases susceptibility to premature responding, while low DA increases preference for immediately available rewards over larger but more distal or difficult to attain ones. The evidence in neurologically intact humans is not incompatible with this view but is less extensive.

\section{IMPULSIVITY SUBTYPES}

Impulse-control is a multifaceted construct (Solanto et al., 2001; Brewer and Potenza, 2008). One common demarcation separates (1) impulsive choice, defined as "actions initiated without due deliberation of other possible options or outcomes"; and (2) impulsive action, defined as behaviors that are "premature, mistimed, difficult to suppress and control" (Dalley et al., 2008). Impulsive action, in turn, might be subdivided into (a) premature responding; and (b) the inability to inhibit an initiated response. These subtypes are based on behavioral and cognitive requirements to perform the tasks used in research experiments (Winstanley et al., 2006), and disturbances are seen in a wide range of psychiatric disorders, such as attention deficit/hyperactivity disorder, pathological gambling and substance use disorders (American Psychiatric Association, 2013). There is compelling evidence that DA plays an important, if not fully understood, role in each of these disorders, and, moreover, of a causal relationship between DA agonist medication and the onset of various impulse-control problems such as pathological gambling, hypersexuality, compulsive shopping, compulsive drug-seeking, and binge eating (Gallagher et al., 2007; Dagher and Robbins, 2009; Moore et al., 2014).

In laboratory animals impulsive action has been assessed most commonly with the stop-signal task (SST; Logan et al., 1984), 
the go/no-go task (de Wit et al., 2002), the 5-CSRT; Robbins, 2002, the DRL task (e.g., Seiden et al., 1979), and the simple reaction time task (Amalric and Koob, 1987). Versions of all five tasks have been used in laboratory rodents and humans, but the 5-CSRT literatures consist predominantly of animal studies (Winstanley, 2011). While all tasks can measure premature responding, the SST and go/no-go tasks were also designed to measure the ability to inhibit a motor response. The go/nogo task measures the ability to inhibit responses to inappropriate cues, whereas the SST measures the speed at which an already initiated response can be inhibited (Eagle and Baunez, 2010). The 5-CSRT, DRL and simple reaction time tasks involve "waiting" before making a response to obtain a reinforcer (see Box 1 for a more detailed description of these tasks). Impulsive choice, in comparison, reflects the preference for immediately available small rewards over larger but more distal ones, and is commonly evaluated with temporal discounting procedures such as the delay discounting task (DDT; Ainslie, 1975), effort discounting paradigms (e.g., Floresco et al., 2008), probabilistic discounting tasks (e.g., St Onge and Floresco, 2009) and gambling-like tasks, such as the Iowa Gambling Task (IGT; Bechara et al., 1994; see Box 2 for more detailed descriptions of these tasks).

While multiple other neurotransmitters also influence performance on these tasks (Winstanley et al., 2003; Winstanley, 2011), the focus of the present review is on the role of DA, both in laboratory animals and in healthy human subjects. With a few noted exceptions, we will specifically review studies on the effects of acutely administered drugs given systemically.

\section{DOPAMINERGIC MANIPULATIONS AND IMPULSIVE BEHAVIOR \\ IMPULSIVE ACTION (PREMATURE RESPONDING; INABILITY TO STOP AN INITIATED BEHAVIOR) \\ Animal studies}

In laboratory rodents, a fairly consistent finding has been that DA augmenting drugs increase premature responding (see Table 1). This effect has been observed on the 5-CSRT following the acute administration of amphetamine $(0.15-1.6 \mathrm{mg} / \mathrm{kg}$, i.p.; Cole and Robbins, 1987; Harrison et al., 1997; van Gaalen et al., 2006b, 2009; Pattij et al., 2007; Loos et al., 2010; Fletcher et al., 2011; Baarendse and Vanderschuren, 2012; see also Zeeb et al., 2009), methylphenidate $(2.0,2.5,5.0 \mathrm{mg} / \mathrm{kg}$, i.p.; Navarra et al., 2008; Milstein et al., 2010), cocaine (5-20 mg/kg, i.p.; van Gaalen et al., 2006b; Winstanley et al., 2007; Fletcher et al., 2011), and the selective DA reuptake inhibitor, GBR 12909 (1.0, 2.5, 5.0, 10.0 mg/kg, i.p.; van Gaalen et al., 2006b; Loos et al., 2010; Baarendse and Vanderschuren, 2012; Fernando et al., 2012). Two studies reported a null effect for methylphenidate $(0.3-4.0 \mathrm{mg} / \mathrm{kg}$, i.p. $)$ on premature responding, although a nonsignificant trend of a dosedependent increase was found (Fernando et al., 2012; Paterson et al., 2012). Orally administered modafinil (32, 64, $128 \mathrm{mg} / \mathrm{kg})$ failed to increase impulsive action on the standard 5-CSRT, but did so at the two highest doses on a modified version with shorter stimulus duration and lower stimulus intensity (Waters et al., 2005). On the DRL, increased premature responding has

\section{BOX 1 | Measures of impulsive action.}

1. The five-choice serial reaction time task (5-CSRT; Robbins, 2002) A visual stimulus is presented at one of five locations, and responding must be withheld until the stimulus signals that responding is appropriate. Impulsive behavior is measured by the number of responses made before the onset of the stimulus.

2. The differential reinforcement of low rates (DRL) of responding task (e.g., Seiden et al., 1979)

To obtain a reinforcer, subjects are required to withhold from responding for a fixed period of time and then to respond. Delays during which subjects are required to withhold from responding typically range from $10 \mathrm{~s}$ (DRL 10) to $72 \mathrm{~s}$ (DRL 72). Premature responses on this task consist of those made before this period of time has elapsed. Such responses reset the trial and are not reinforced. In some instances, subjects are required to respond after a fixed period of time has elapsed, but the response must occur within a certain delay (e.g., DRL 10-14), otherwise late responses are not reinforced.

\section{The simple reaction time task (Amalric and Koob, 1987)}

Each trial begins when subjects press on a lever. They must hold the lever down for a variable period of time, until a visual or auditory stimulus is presented. Following the presentation of this stimulus, subjects must release the lever within a pre-determined delay. Incorrect trials consist of those during which the lever was released prior to the stimulus onset (i.e., anticipated or premature responses) or after the delay has elapsed following the stimulus onset (i.e., delayed responses).

\section{The stop-signal task (SST; Logan et al., 1984)}

Subjects initiate a motor response following a go signal, and reaction times (RT) are determined. On a small proportion of trials, a stop signal follows the go signal. Sometimes the stop signal appears well before the subject's RT limit, thereby providing sufficient time to inhibit the response. On other trials though the stop signal occurs very close to when the subject would normally respond, providing little time to inhibit the behavior. The longer the interval required to inhibit responses, the longer the stop signal response time (SSRT), and the poorer the inhibitory control.

\section{The go/no-go task (de Wit et al., 2002)}

Only one signal is presented per trial. The go signal is much more frequent than the no-go signal, thus priming subjects to initiate a motor response. On this task, poor inhibitory control is quantified by the number of responses on no-go trials (i.e., errors of commission).

been reported for schedules varying from 10 to $72 \mathrm{~s}$ following acute administration of amphetamine $(0.5 \mathrm{mg} / \mathrm{kg}$, s.c.; $0.3-4.0$ mg/kg, i.p.; Sanger et al., 1974; Canon and Lippa, 1977; Seiden et al., 1979; Britton and Koob, 1989; Wenger and Wright, 1990; van Hest et al., 1992; Richards et al., 1993; Sabol et al., 1995; Bizot, 1998; Wiley et al., 2000; Ferguson et al., 2001; Liao and Cheng, 2005; Cheng and Liao, 2007), methylphenidate (2.0$20.0 \mathrm{mg} / \mathrm{kg}$, i.p.; Seiden et al., 1979; Ferguson et al., 2001), cocaine (1, 2, $4 \mathrm{mg} / \mathrm{kg}$, i.v.; 10, 20, $40 \mathrm{mg} / \mathrm{kg}$, p.o.; 3-16 $\mathrm{mg} / \mathrm{kg}$, i.p.; Woolverton et al., 1978; Wenger and Wright, 1990; Ma et al., 1999; Wang et al., 2001; Cheng et al., 2006), and modafinil (64, $128 \mathrm{mg} / \mathrm{kg}$, i.p.; Bizot, 1998). On simple reaction time tasks, increased premature responding has been observed in response to amphetamine administration $(0.8 \mathrm{mg} / \mathrm{kg}$, s.c.; 


\section{BOX 2 | Measures of impulsive choice.}

\section{The delay discounting task (DDT; Ainslie, 1975)}

Subjects must choose between a small reinforcer delivered immediately and a large reinforcer delivered after a given delay. On separate trials, the value of the immediate reinforcer or the delay to obtain the large reinforcer is changed, until subjects reach a point where both options are chosen equally. This point is called the indifference point. This step is repeated several times to obtain multiple points, which yield a hyperbolic discounting curve. The measure of interest is the steepness of that curve, which is called the discounting rate, with greater steepness indicating greater discounting of delayed reinforcers (i.e., impulsive choice). Note that in studies conducted in human subjects, reinforcers can be hypothetical or real.

\section{Effort discounting tasks (e.g., Floresco et al., 2008)}

Subjects must choose between a small reinforcer that can be easily obtained and a large reinforcer that requires greater effort to obtain. On separate trials, the value of the easy reinforcer or the amount of effort required to obtain the large reinforcer is changed, until subjects reach a point where both options are chosen equally. This point is called the indifference point. This step is repeated several times to obtain multiple points, which yield a hyperbolic discounting curve. The measure of interest is the steepness of that curve, which is called the discounting rate, with greater steepness indicating greater effort discounting, meaning that subjects are less willing to exert effort to obtain the larger reinforcer (i.e., impulsive choice).

3. Probability discounting tasks (e.g., St Onge and Floresco, 2009) Subjects must choose between a small reinforcer that is delivered with greater certainty, and a larger, more uncertain reinforcer that is delivered according to various probabilities. On separate trials, the value of the small reinforcer or the probability at which the large reinforcer is delivered is changed, until subjects reach a point where both options are chosen equally. This point is called the indifference point. This step is repeated several times to obtain multiple points, which yield a hyperbolic discounting curve. The measure of interest is the steepness of that curve, which is called the discounting rate, with greater steepness indicating greater probability discounting, meaning that subjects choose the large reinforcer despite low probabilities of its delivery (i.e., impulsive choice).

\section{The lowa Gambling Task (IGT; Bechara et al., 1994)}

Subjects are asked to pick cards from four decks, two of which result in overall gain due to frequent small gains and infrequent small losses, and the remaining two decks resulting in overall loss due to frequent large gains but infrequent larger losses. As subjects are not explicitly told about these contingencies, they must learn the patterns of wins and losses associated with each deck, and guide their choice toward the advantageous decks (i.e., those providing smaller immediate rewards in prospect of avoiding a long-term loss) to obtain a positive outcome. Therefore, the IGT requires learning for optimal performance (Fellows and Farah, 2005).

$1.0 \mathrm{mg} / \mathrm{kg}$, i.p.; Baunez et al., 1995; Blokland et al., 2005). Approach toward the reward persists with sustained increases in DA transmission (Salamone et al., 1991, 2001; Robinson and Berridge, 2008; Howe et al., 2013; Leyton and Vezina, 2014).
Dopamine antagonists have the opposite effects of agonists. Decreased premature responding has been observed on the 5CSRT following acute administration of the DA D1 receptor antagonist, SCH 23390 (0.05, $0.075 \mathrm{mg} / \mathrm{kg}$, i.p. and 10-30 $\mu \mathrm{g} / \mathrm{kg}$, i.p.; Harrison et al., 1997; van Gaalen et al., 2006b), while D2 antagonists, such as sulpiride $(40,60 \mathrm{mg} / \mathrm{kg}$, i.p.) and eticlopride $(0.06-0.1 \mathrm{mg} / \mathrm{kg}$, i.p.), increase the latency to initiate a response, thus reducing the propensity to impulsive responding (Harrison et al., 1997; van Gaalen et al., 2006b; see Table 2). This apparent differential contribution of D1 and D2 receptors to impulsive responding might reflect their proposed roles in approach behaviors more generally, with D1 receptor stimulation thought to induce behavioral activation and heighten the signalto-noise salience of appetitive cues while D2 stimulation releases the "brake" on behavior (Frank, 2005; Tai et al., 2012). Importantly, re-engaging this hypothesized "brake" with eticlopride also diminishes the ability of DA augmenters to increase premature responding (van Gaalen et al., 2006b). On the DRL, the number of premature responses was diminished by acute doses of $\mathrm{SCH}$ $23390(0.02-0.1 \mathrm{mg} / \mathrm{kg}$, i.p.) and the D2 antagonists raclopride (0.2-0.5 mg/kg, i.p.; Liao and Cheng, 2005; Cheng and Liao, 2007) and haloperidol (0.25, $0.5 \mu \mathrm{g} / \mathrm{kg}$, s.c.; 0.16, $0.32 \mathrm{mg} / \mathrm{kg}$, i.p.; Britton and Koob, 1989; van Hest et al., 1992). On simple reaction time tasks, several effects have been reported following acute treatment with DA antagonists. Decreased premature responses have been observed in response to SCH $23390(0.025-0.2 \mathrm{mg} / \mathrm{kg}$, i.p.), raclopride $(0.05-0.8 \mathrm{mg} / \mathrm{kg}$, i.p.) and haloperidol (0.05-0.4 $\mathrm{mg} / \mathrm{kg}$, i.p.; Marrow et al., 1993). Dopamine antagonists can also impair performance by lengthening reaction times (RT), resulting in a greater number of delayed responses while leaving premature responding intact. These effects have been seen following administration of eticlopride $(0.01,0.02 \mathrm{mg} / \mathrm{kg}$, s.c.; Smith et al., 2000), flupenthixol (0.2, 0.4 mg/kg, i.p.; Amalric and Koob, 1987), and raclopride (50-200 $\mu \mathrm{g} / \mathrm{kg}$, s.c.; $0.05 \mathrm{mg} / \mathrm{kg}$, s.c.; $0.8 \mathrm{mg} / \mathrm{kg}$, i.p.; Amalric et al., 1993; Marrow et al., 1993; Baunez et al., 1994, 1995). However, null effects have also been reported in response to eticlopride $(0.01,0.03 \mathrm{mg} / \mathrm{kg}$, i.p.; Blokland et al., 2005), SCH 23390 (5, 10, $20 \mu \mathrm{g} / \mathrm{kg}$, s.c.; Amalric et al., 1993) and flupenthixol $(0.05,0.1,0.2,0.4 \mathrm{mg} / \mathrm{kg}$, i.p.; Marrow et al., 1993). These slightly discrepant results might reflect differences in the specifics of the task, such as the delay after the onset of the stimulus, the behavior performed (e.g., nose poke vs. lever press), or the effect of these compounds on motivation. For example, Blokland et al. (2005) found that the highest dose of eticlopride administered in their study $(0.03 \mathrm{mg} / \mathrm{kg}$, i.p. $)$ decreased motivation to obtain food, as assessed by a progressive-ratio schedule.

In studies using the SST and go/no-go tasks, the results have been similar. An acute dose of GBR 12909 (5, $10 \mathrm{mg} / \mathrm{kg}$, i.p.) accelerated both go and stop SST RT leading to an increased number of premature responses (Bari et al., 2009). Although low to moderate doses of amphetamine $(0.5,1.0 \mathrm{mg} / \mathrm{kg}$, i.p. in mice; Loos et al., 2010) and cocaine $(5,10 \mathrm{mg} / \mathrm{kg}$, i.p. in rats; Paine and Olmstead, 2004) had no effect, a higher dose of cocaine (15 mg/kg, i.p.) increased premature responding, as indexed by increased commission errors (responding during no-go trials; Paine and Olmstead, 2004). 


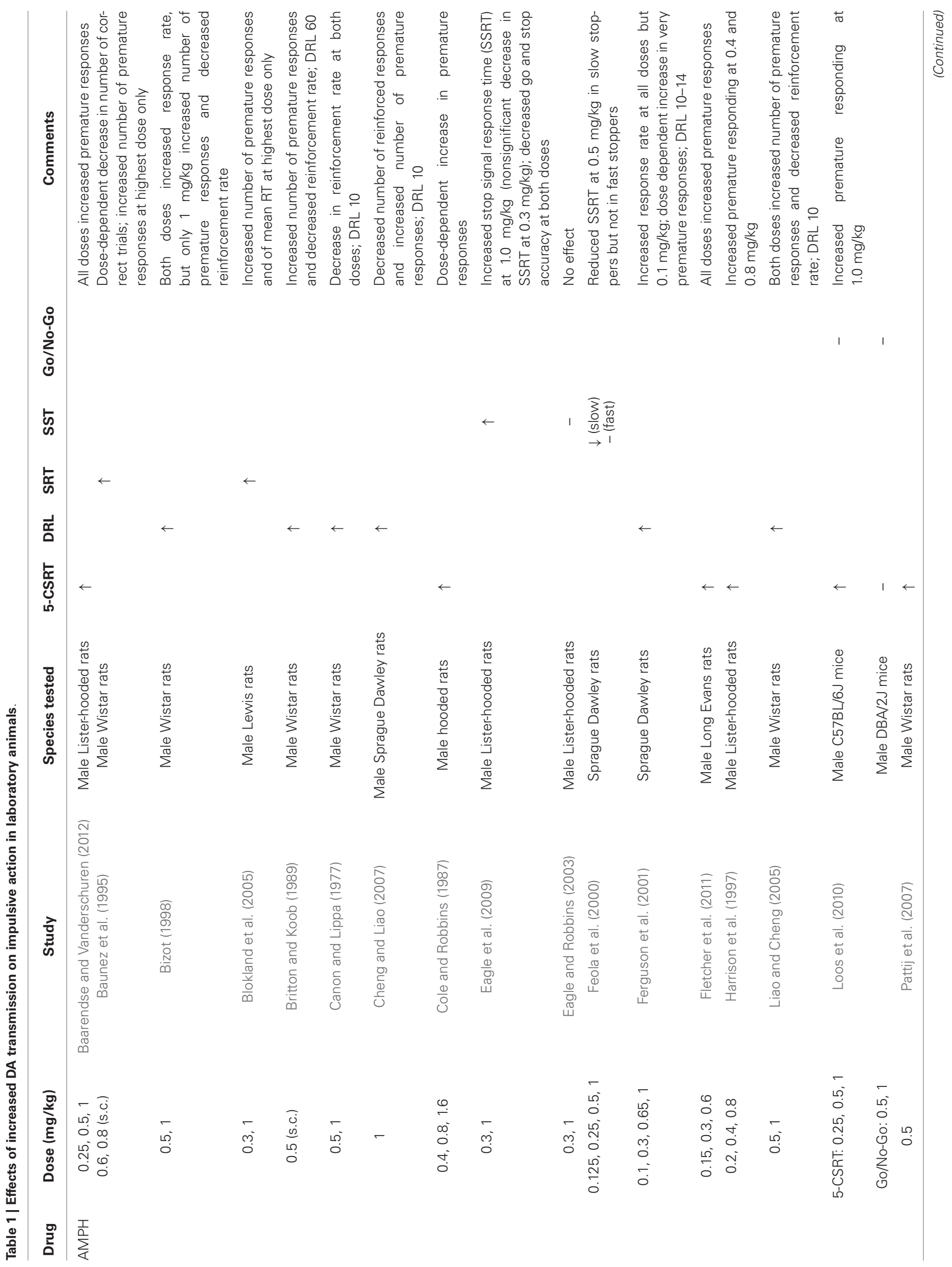




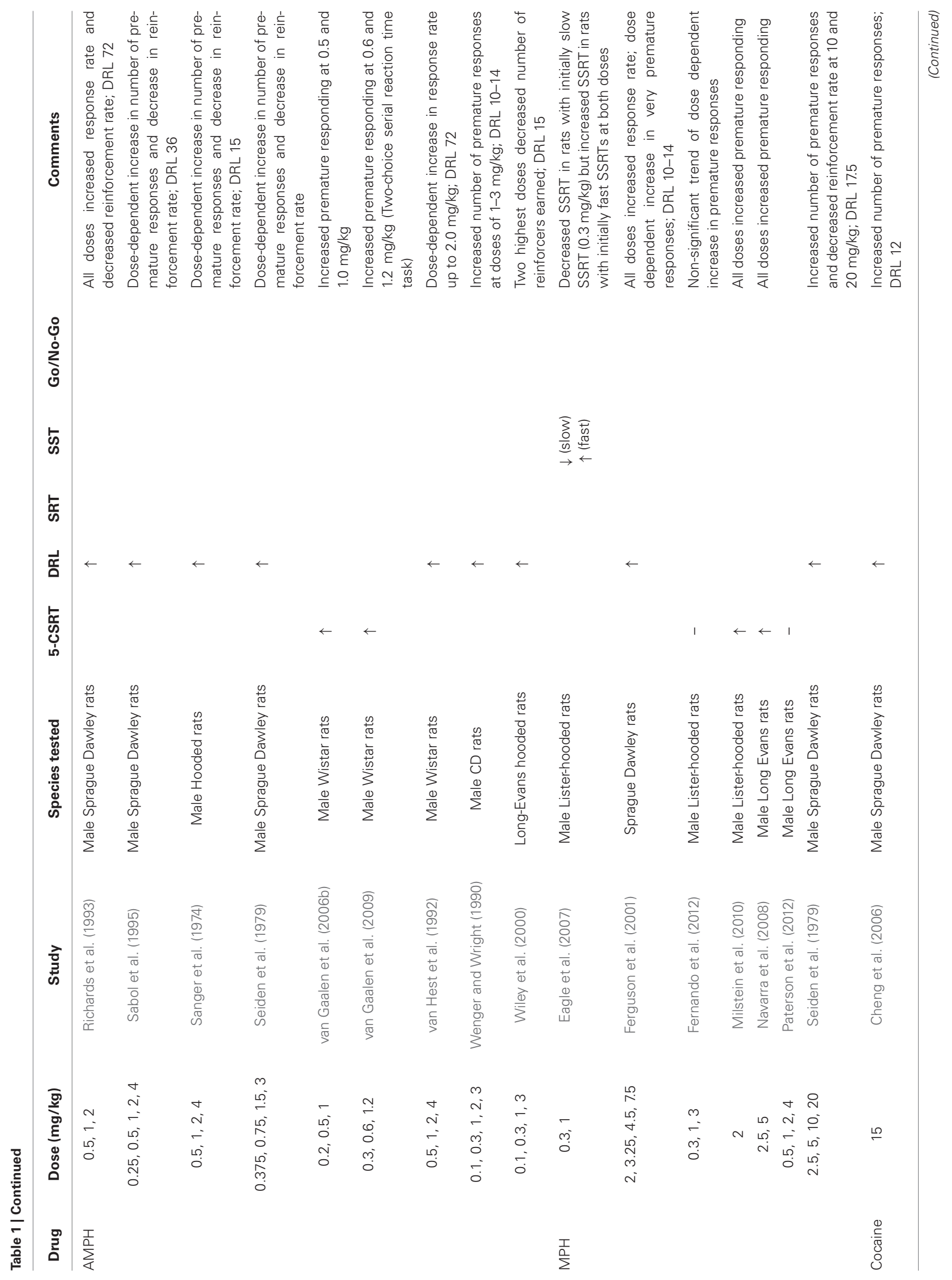




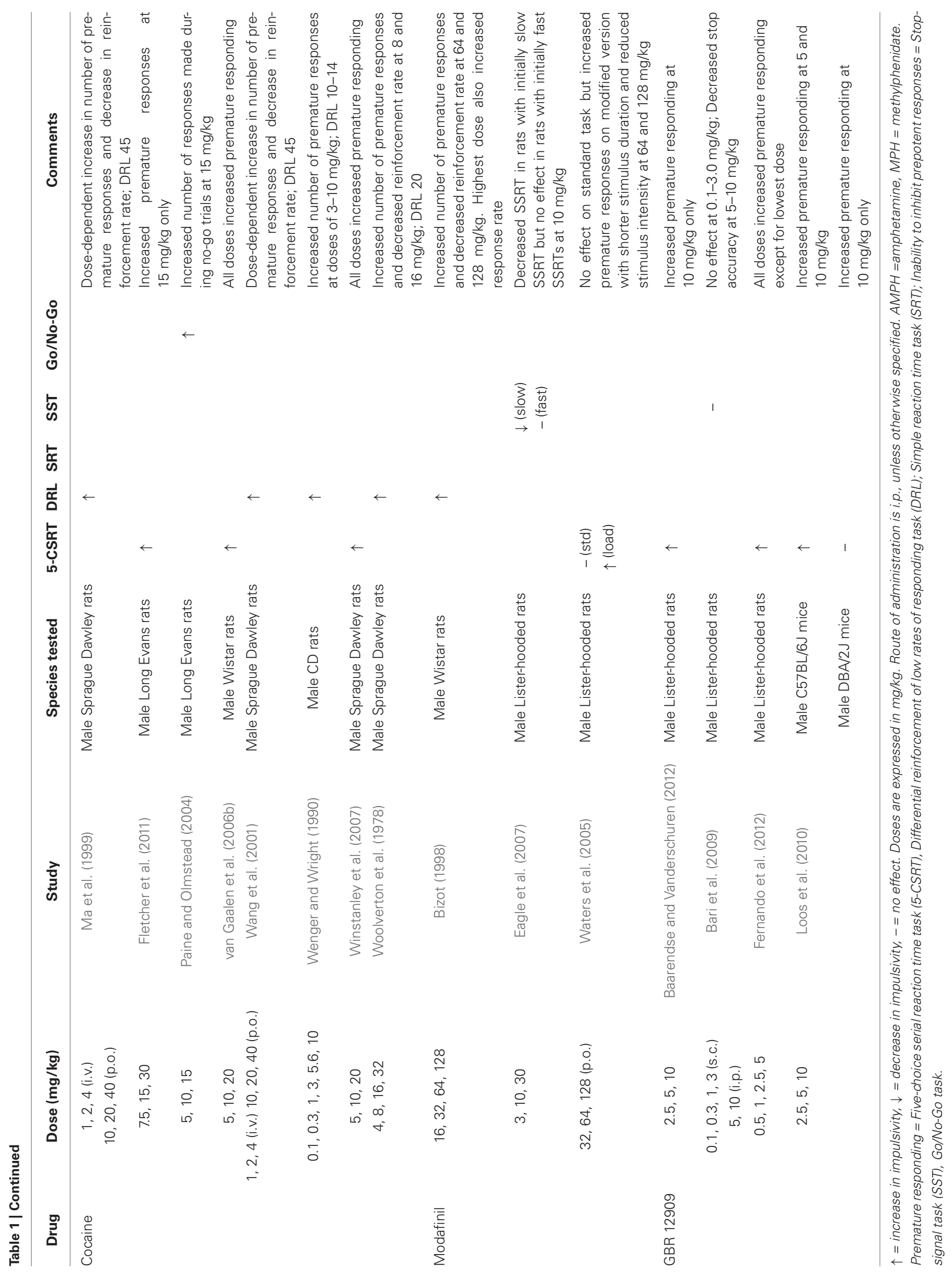




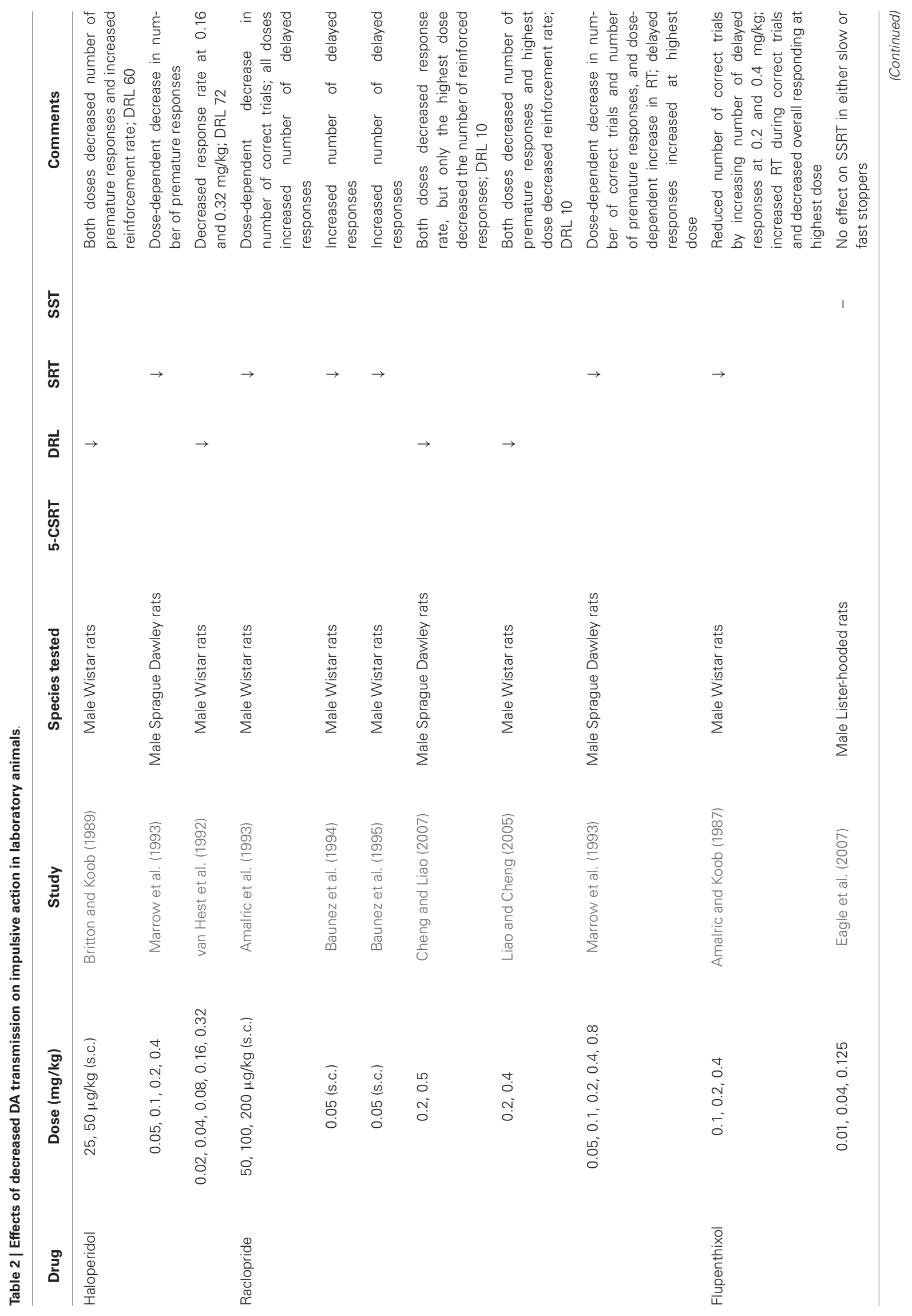




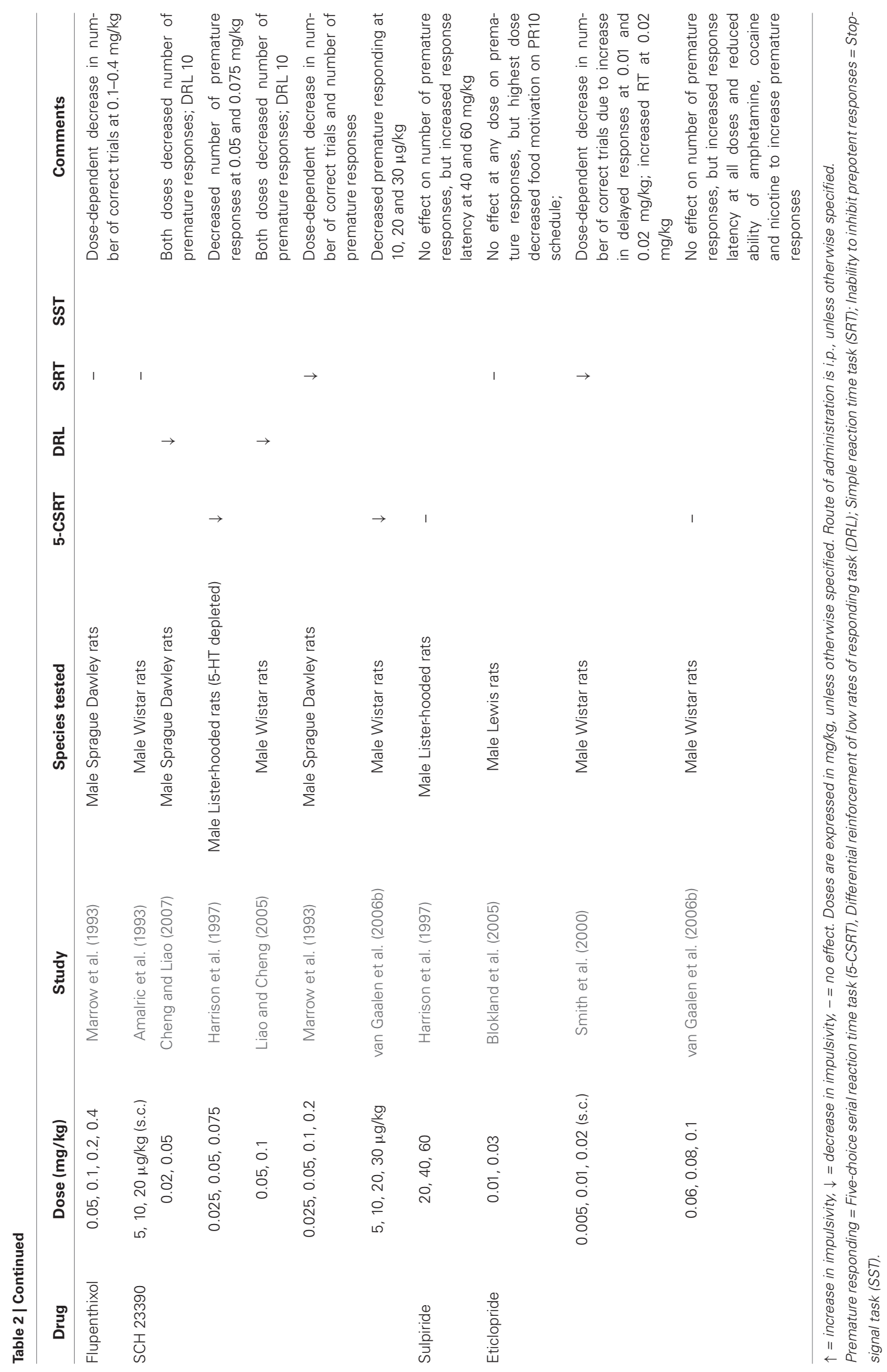


The ability to inhibit an initiated response is also altered by DAergic drugs but the pattern of effects differs compared to those seen on premature responding. In studies using the SST, the effects of amphetamine, methylphenidate and modafinil depended on whether the animals had slow or fast inhibitory responses under placebo. In rats with poor inhibitory control (slow responders), all three drugs improved performance by shortening the time required to inhibit an initiated response (Feola et al., 2000; Eagle and Robbins, 2003; Eagle et al., 2007, 2009). The opposite effect was observed in fast responders (0.3, $1.0 \mathrm{mg} / \mathrm{kg}$ modafinil, i.p.; Eagle et al., 2007). Administration of the D1/D2 receptor antagonist flupenthixol $(0.01-0.125 \mathrm{mg} / \mathrm{kg}$, i.p.), in comparison, had no effect on the ability to inhibit responses on the SST in either fast or slow responders (Eagle et al., 2007).

Together then, the weight of evidence from these studies in laboratory rodents indicates that elevations in DA transmission can have two main effects on impulsive actions: they increase premature responding while also improving the ability to inhibit prepotent responses in impulsive animals.

\section{Human studies}

To our knowledge, there are no studies of the effects of DA augmenters on premature responding in healthy humans. There is a small literature, though, describing effects on the ability to inhibit initiated responses (Table 3 ). In agreement with studies in laboratory animals, the acute administration of low-to-moderate doses of oral $d$-amphetamine (10-20 mg) had differential effects on SST performance depending on the subject's baseline performance. In individuals with poor baseline inhibitory control (i.e., slow stoppers), $d$-amphetamine improved the ability to inhibit an initiated response, while having no effect in fast stoppers (de Wit et al., 2000, 2002). A similar pattern has been observed on the go/no-go task, where more impulsive subjects at baseline showed a reduction in the number of commission errors following both 10 and $20 \mathrm{mg}$ of $d$-amphetamine (de Wit et al., 2002). These results are consistent with those seen in children and adults with attention-deficit/hyperactivity disorder, where the ability to inhibit responses is improved following the administration of oral methylphenidate (Tannock et al., 1989; Aron et al., 2003). They are also in accordance with a recent study by Aarts et al. (2014), in which individuals with greater DA synthesis capacity performed poorly when they anticipated a large reward on a modified Stroop task. The authors proposed that DA release in response to the large rewards may "overdose" an already DA-rich system, and have detrimental effects on performance. These detrimental effects would potentially emerge with higher doses of $d$-amphetamine in fast stoppers. In one study, methylphenidate administration (40 mg) did not affect healthy adults' performance on the SST or on the go/no-go task, but it reduced intra-individual RT which is indicative of increased attention (Costa et al., 2013). The lack of effect on overall performance could be explained by the low rate of inhibition errors in this particular sample of participants.

Decreasing DA release, in comparison, using the acute phenylalanine/tyrosine depletion method, has been reported to increase go/no-go commission errors, particularly in response to reward cues (Leyton et al., 2007), and diminish the ability to supress incorrect impulses, as measured with a sensitive electromyography index (Ramdani et al., 2014). In the converse experiment, administration of the DA precursor, tyrosine (2.0 g, p.o.), improved SST performance by reducing the time required to inhibit initiated responses (Colzato et al., 2014). This effect of tyrosine might reflect greater cognitive control in the prefrontal cortex, as the same research group has found that tyrosine improves performance on a demanding condition of the $N$-Back task (Colzato et al., 2013) while tyrosine depletion tended to reduce $N$-Back performance in people carrying the low activity met allele of the gene encoding for the enzyme, catecholO-methyltransferase (Kelm and Boettiger, 2013). These effects on the ability to inhibit prepotent responses, though, have not been observed consistently in other studies following tyrosine depletion (McLean et al., 2004; Lythe et al., 2005) or following administration of $d$-amphetamine $(7.5-15 \mathrm{mg} / \mathrm{kg}$, p.o.; Fillmore et al., 2005) or the DA agonist, pramipexole $(0.25-0.5 \mathrm{mg}$, p.o.; Hamidovic et al., 2008). It remains to be tested whether these divergent findings reflect baseline differences in performance or the need for more sensitive measures (Ramdani et al., 2014).

\section{IMPULSIVE CHOICE (CHOOSING SMALL IMMEDIATELY AVAILABLE REWARDS OVER DELAYED OR MORE DIFFICULT TO ATTAIN LARGE REWARDS) \\ Animal studies}

In most studies, the ability to delay responding to receive a larger reward is disrupted by decreased DA transmission (Cardinal et al., 2000; Wade et al., 2000; Denk et al., 2005; van Gaalen et al., 2006a; Floresco et al., 2008; Koffarnus et al., 2011) and improved by modest increases (see Tables 4, 5). Beneficial effects have been observed following the administration of methylphenidate (1.0, $3.0 \mathrm{mg} / \mathrm{kg}$, i.p.; van Gaalen et al., 2006a), cocaine (7.5, 15 mg/kg, i.p.; Winstanley et al., 2007), GBR 12909 (5 mg/kg, i.p.; van Gaalen et al., 2006a) and amphetamine (0.25-0.6 mg/kg, i.p.; Cardinal et al., 2000; Isles et al., 2003; Winstanley et al., 2003; Floresco et al., 2008). Following the administration of higher doses of amphetamine (0.5-2.3 mg/kg, i.p.; $1.0 \mathrm{mg} / \mathrm{kg}$, s.c.), the reported results are more variable, and both disruptions (Charrier and Thiébot, 1996; Evenden and Ryan, 1996; Cardinal et al., 2000; Isles et al., 2003; Helms et al., 2006; Koffarnus et al., 2011; Maguire et al., 2014) and improvements have been described (Wade et al., 2000; Winstanley et al., 2003). A high dose of pramipexole $(0.32 \mathrm{mg} / \mathrm{kg}$, s.c. $)$ increased preference for the smaller reinforcer (Koffarnus et al., 2011), whereas moderate to high doses of methylphenidate $(1.0-4.0 \mathrm{mg} / \mathrm{kg}$, i.p.) had the opposite effect (Paterson et al., 2012). Interestingly, the effects of amphetamine and methylphenidate seem to depend, at least in part, on the order of presentation of delay. Disruptions have been reported when animals are exposed to the various delays in descending order (Maguire et al., 2014; Tanno et al., 2014), whereas improvements (Tanno et al., 2014) or a null effect (Maguire et al., 2014) have been described when the delays are presented in ascending order. It has been proposed that amphetamine and methylphenidate might have induced perseverative responding early in the sessions when delays were 


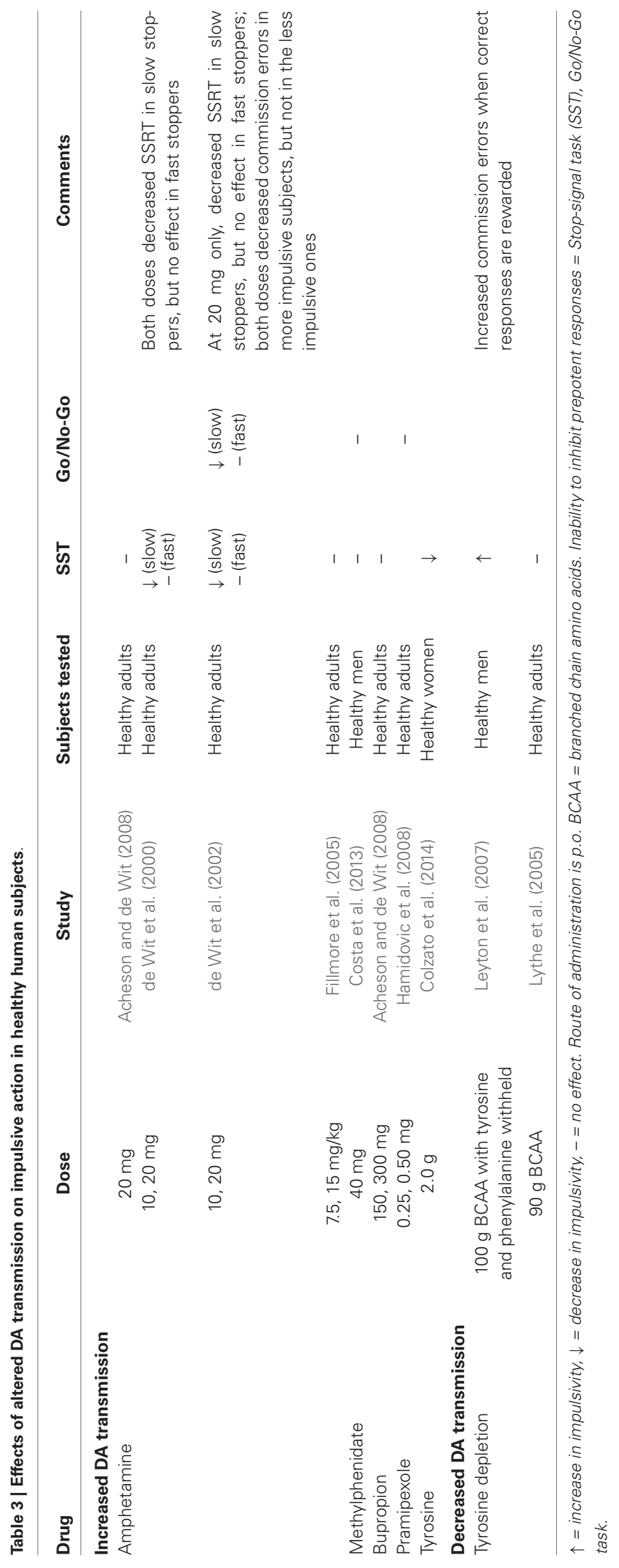




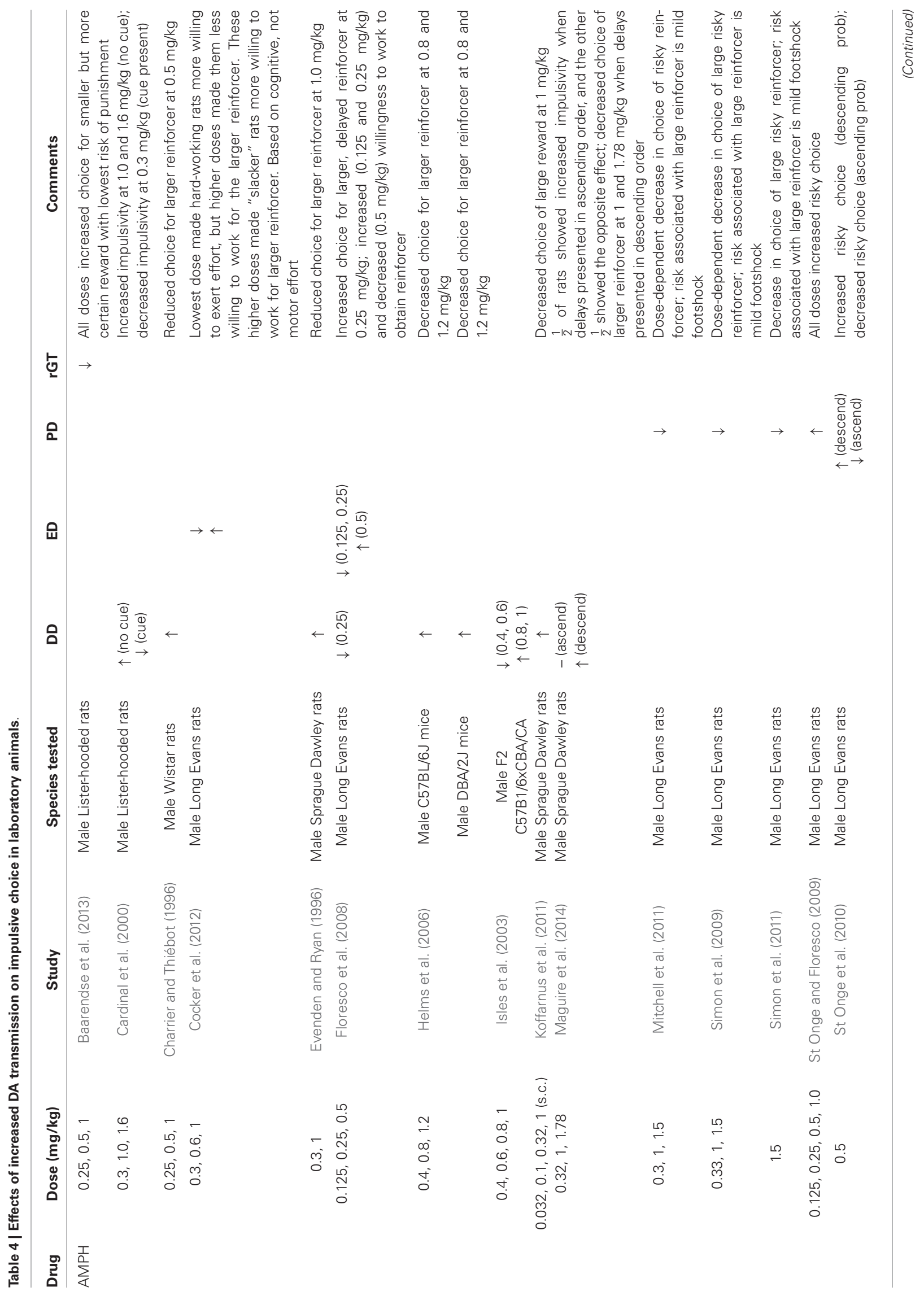




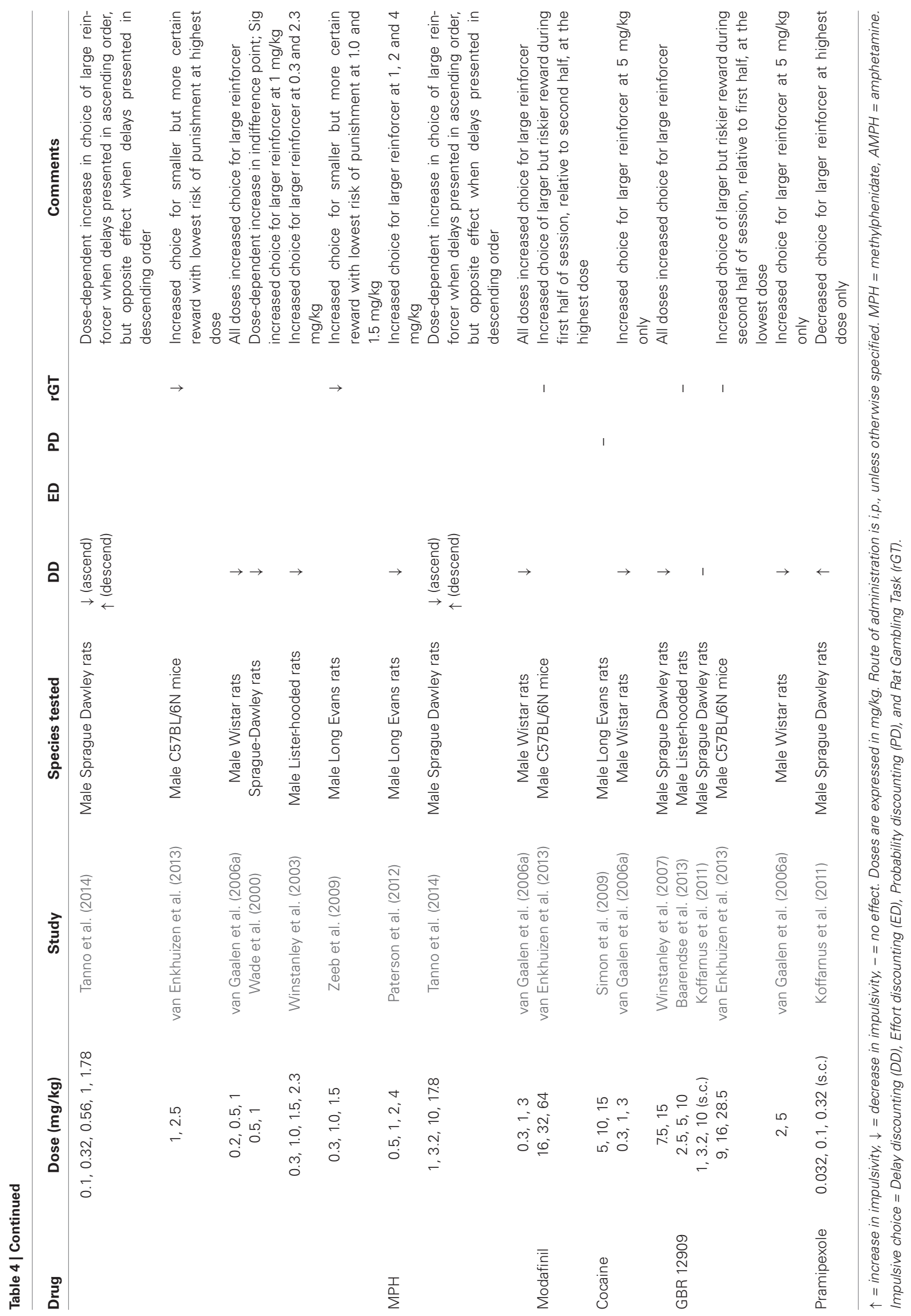




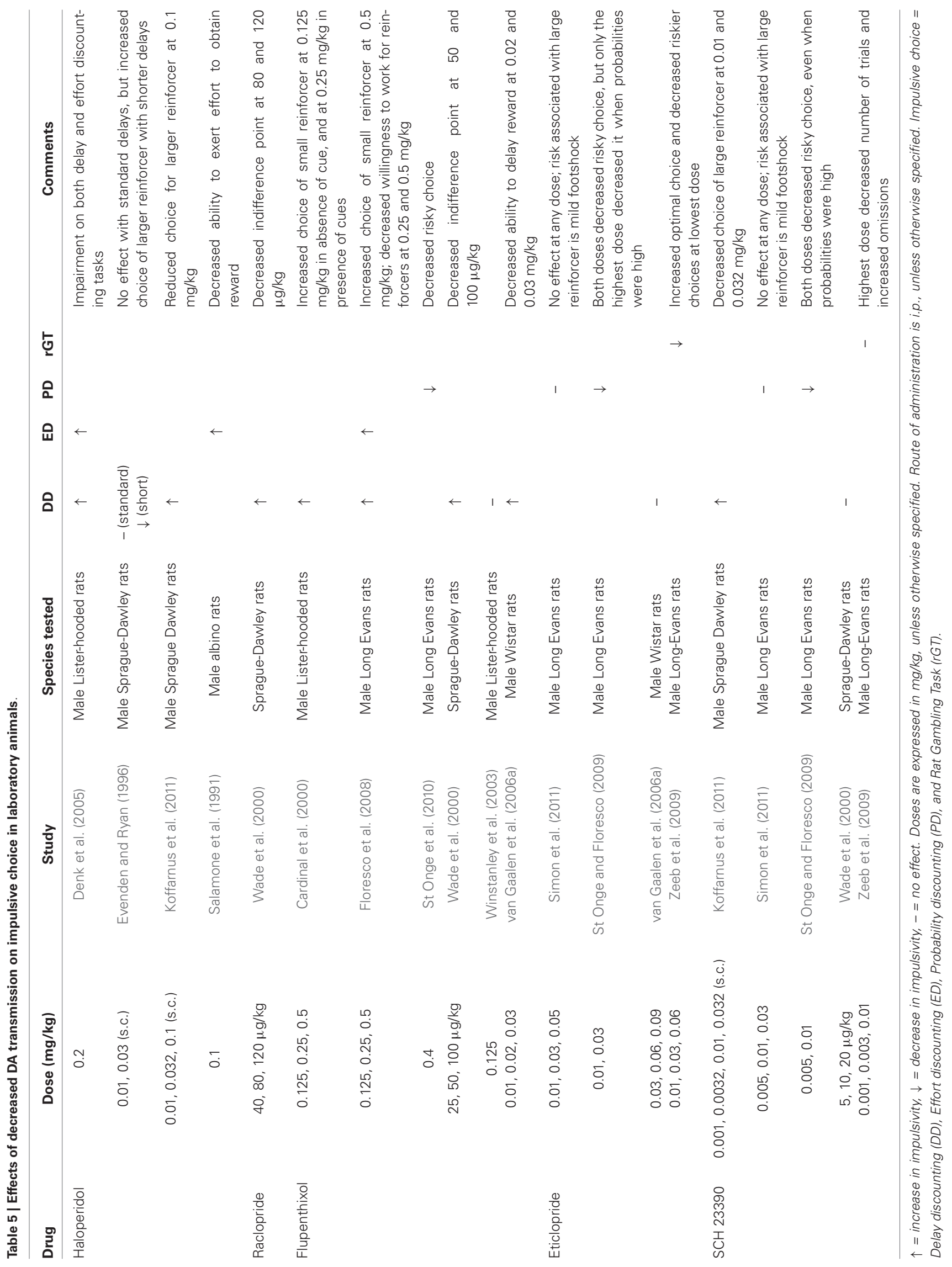


presented in descending order, and that continued perseverative responding was responsible for the enhanced choice of the smaller, immediate reinforcer throughout the sessions (Tanno et al., 2014).

Lending further support to the association between low DA and impulsive choice, numerous studies have found that laboratory animals choose smaller, immediate rewards more frequently following the administration of DA antagonists (see Table 5), including haloperidol (0.1-0.2 mg/kg, i.p.; $0.1 \mathrm{mg} / \mathrm{kg}$, s.c.; Denk et al., 2005; Koffarnus et al., 2011), raclopride (80, $120 \mu \mathrm{g} / \mathrm{kg}$, i.p.; Wade et al., 2000), flupenthixol (0.02, 0.03, 0.125, $0.5 \mathrm{mg} / \mathrm{kg} ; 50,100 \mu \mathrm{g} / \mathrm{kg}$, i.p.; Cardinal et al., 2000; Wade et al., 2000), and SCH 23390 (0.02-0.03 mg/kg, i.p.; 0.01, $0.032 \mathrm{mg} / \mathrm{kg}$, s.c.; van Gaalen et al., 2006a; Koffarnus et al., 2011). Very low doses of haloperidol (0.01, $0.03 \mathrm{mg} / \mathrm{kg}$, s.c.), in comparison, had no effect on impulsive choice in response to standard delays, but decreased impulsive choice in response to delays that were much shorter than usual (Evenden and Ryan, 1996).

Dopamine antagonists, such as haloperidol $(0.1-0.2 \mathrm{mg} / \mathrm{kg}$, i.p.) and flupenthixol (0.25-0.5 mg/kp, i.p.) also increase effort discounting (Salamone et al., 1991; Denk et al., 2005; Floresco et al., 2008) and decrease the willingness to sustain effort as measured by progressive ratio breakpoints for natural rewards, such as food (Salamone et al., 2009) and pharmacological rewards, such as cocaine (Roberts et al., 2013). Interestingly, Cocker et al. (2012) reported evidence for differential effects of amphetamine on effort discounting in rats that exert high vs. low effort at baseline. In hard-working rats, a low dose $(0.3 \mathrm{mg} / \mathrm{kg}$, i.p. $)$ increased their willingness to work to obtain the large reward, but higher doses $(0.6,1.0 \mathrm{mg} / \mathrm{kg}$, i.p.) had the opposite effect. In the so-called "slacker" rats, these high doses enhanced their willingness to exert effort to obtain the large reward. These results are consistent with Aarts et al. (2014) findings of reduced cognitive control when DA levels are too high in individuals with greater DA synthesis capacity. It is possible that having too much DA impaired cognitive control in a way that made the smaller, but immediately available reward more appealing than the larger reward, which required greater effort to obtain.

Compared to temporal and effort discounting tasks, the results overall differ in probabilistic tasks where rats choose between a smaller but certain reward, and a larger but uncertain reward. In such tasks, low DA states induced by administration of flupenthixol $(0.4 \mathrm{mg} / \mathrm{kg}$, i.p.), eticlopride $(0.01-0.03 \mathrm{mg} / \mathrm{kg})$, and SCH 23390 (0.005-0.01 mg/kg, i.p.) decreased risky choices, even when probabilities of obtaining the larger reward were high (St Onge and Floresco, 2009; St Onge et al., 2010). In comparison to these effects of DA antagonists, the administration of small to moderate doses of amphetamine $(0.125-1.0 \mathrm{mg} / \mathrm{kg}$, i.p.) shifts choice preferences toward larger, more uncertain reward, even when the probability of delivery is very low (St Onge and Floresco, 2009; St Onge et al., 2010). This effect has been observed when such probabilities are presented in descending order, while the opposite was reported when probabilities increased over time (St Onge et al., 2010). The same research group has also found that low doses of amphetamine reduced delay $(0.25 \mathrm{mg} / \mathrm{kg})$ and effort discounting $(0.125,0.25 \mathrm{mg} / \mathrm{kg}$, i.p. $)$, but that a higher dose $(0.5 \mathrm{mg} / \mathrm{kg}$, i.p. $)$ increased effort discounting, meaning that animals were less willing to exert effort to obtain larger rewards (Floresco et al., 2008).

The above findings suggest that distinct mechanisms underlie delay, effort, and risk discounting. They further highlight that methodological differences in task requirements or the order of presentation of various contingencies can be crucial when interpreting the effects of DA manipulations. Other differences, such as the presence of reward cues during the delay, the type of reinforcer used, and variations in the paradigms, are also worth considering. It is noteworthy that the standard delay discounting paradigm shares features with premature responding tasks such as the 5-CSRT, as both assess the ability to wait in order to get a reinforcer. This is supported by correlations between levels of delay discounting and premature responding in the same rats (Robinson et al., 2009). It is therefore possible that large increases in DA levels, which are known to induce premature responding, interfered with performance on DDT, and as such, masked the potential benefits of DA agonists on the ability to tolerate delays to maximize rewards. It thus appears that having too little or too much DA can impair performance on the delay and effort discounting tasks, whereas high DA might result in greater impulsivity on probabilistic discounting tasks when high probabilities are presented first.

On a recently developed rat version of the IGT, the rGT, $d$-amphetamine $(0.25,0.5,1.0,1.5,2.5 \mathrm{mg} / \mathrm{kg}$, i.p. $)$ increased preference for smaller but certain rewards, resulting in poorer overall outcome (Zeeb et al., 2009; Baarendse et al., 2013; van Enkhuizen et al., 2013), whereas eticlopride $(0.01 \mathrm{mg} / \mathrm{kg}$, i.p.) improved performance by shifting preference toward larger but riskier rewards (Zeeb et al., 2009). It should be noted that rats were punished for losses by timeout periods during which no reward could be earned, which may indicate that amphetamine exerted its effects by increasing sensitivity to punishment. This interpretation is consistent with the observation that $d$-amphetamine $(0.3-1.5 \mathrm{mg} / \mathrm{kg}$, i.p.) dose-dependently decreased choice of a large but risky reinforcer in a probability discounting paradigm in which the risky reinforcer was associated with a mild footshock (Simon et al., 2009, 2011; Mitchell et al., 2011). Together, the above findings suggest that, in these studies, amphetamine affects risk aversion more clearly than reward sensitivity. There are challenges, though, in comparing rewards and punishments on features such as stimulus salience, intensity, etc. Other DA augmenters, such as cocaine (5-15 $\mathrm{mg} / \mathrm{kg}$, i.p.; Simon et al., 2009), GBR 12909 (2.5-28.5 mg/kg, i.p.; Baarendse et al., 2013; van Enkhuizen et al., 2013), and modafinil (16-64 mg/kg, i.p.; van Enkhuizen et al., 2013), as well as the DA antagonist SCH $23390(0.001-0.03 \mathrm{mg} / \mathrm{kg}$, i.p.; Zeeb et al., 2009; Simon et al., 2011), have not significantly affected performance on the rGT or on the probabilistic task with mild footshock.

\section{Human studies}

The DA-impulsive choice literature in healthy humans remains quite small (see Table 6). Most of the evidence-direct and indirect-suggests that low DA states aggravate impulsive choice 


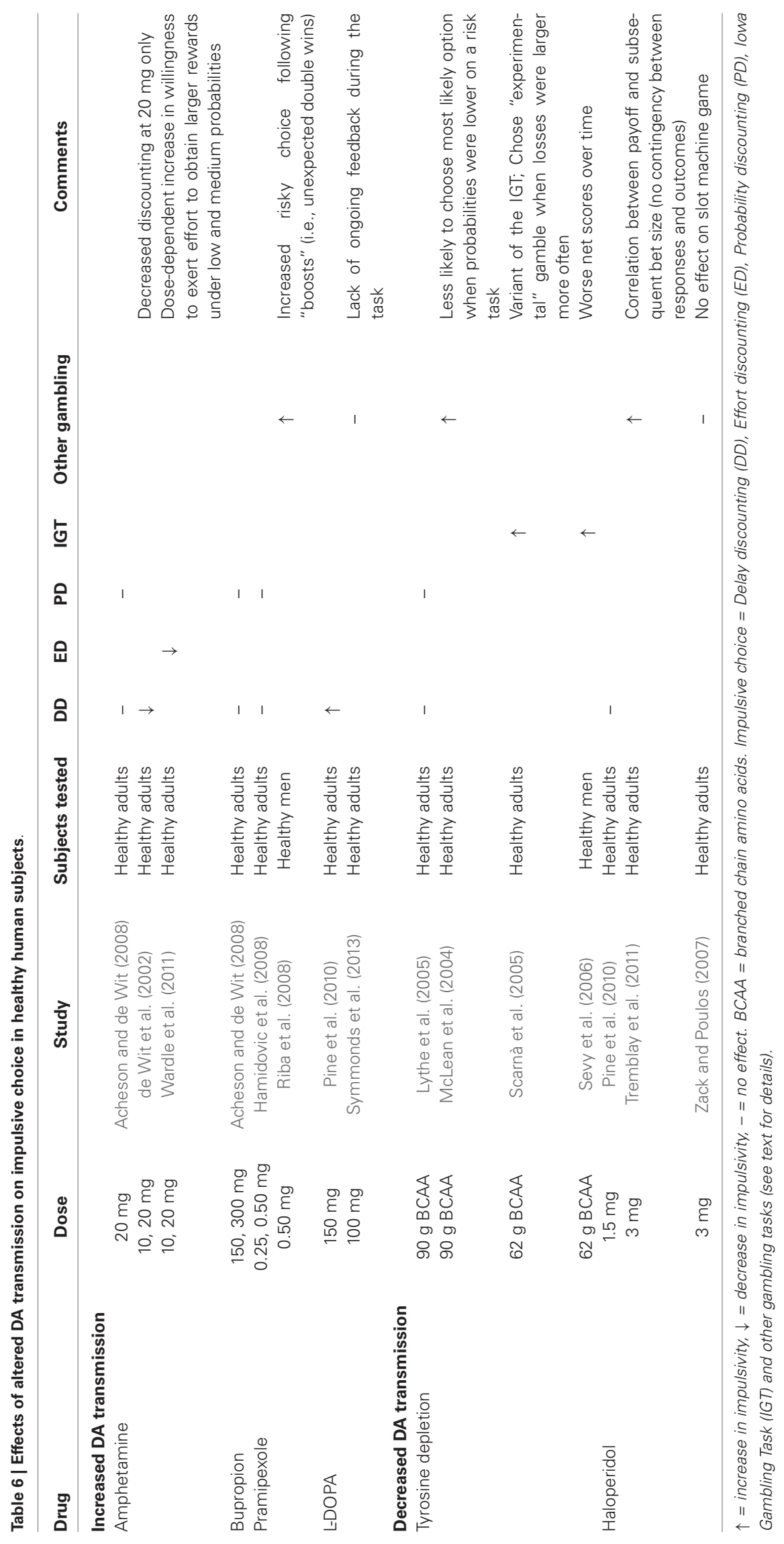


while modest increases improve it (Trifilieff and Martinez, 2014). For example, transiently decreasing DA synthesis, using the tyrosine depletion method, impairs the ability to resist short-term, large gains despite long-term, larger losses on the IGT (Scarnà et al., 2005; Sevy et al., 2006), and decreases the willingness to sustain effort as measured by progressive ratio breakpoints when subjects work for alcohol (Barrett et al., 2008), tobacco (Venugopalan et al., 2011) and money (Cawley et al., 2013). On a guessing game in which probabilities of making the right decision vary, poor performance has also been observed following tyrosine depletion when probabilities were low (McLean et al., 2004), although a lack of effect of tyrosine depletion on probability discounting has also been reported (Lythe et al., 2005). Following administration of haloperidol (3 mg, p.o.), performance was impaired on a betting game in which there were no contingencies between responses and outcomes. Specifically, healthy controls who won money on a given trial subsequently increased the size of their bet on the next trial (Tremblay et al., 2011). Thus, greater reward expectancies resulted in increased risk-taking. However, the same dose of haloperidol did not affect performance on a slot machine game (Zack and Poulos, 2007), nor did a smaller dose $(1.5 \mathrm{mg} / \mathrm{kg}$, p.o. $)$ affect rates of delay discounting in healthy adults (Pine et al., 2010). Pramipexole (0.5 mg, p.o.) increased risky choice on a gambling task following unexpected double wins (Riba et al., 2008). Again, reward expectancies influenced risk-taking. It thus seems that both high and low DA states enhance risk-taking when a large reward is expected.

In comparison to these effects of decreasing DA transmission, healthy volunteers' tolerance for delayed rewards on the DDT was increased by a moderate dose of oral $d$-amphetamine $(20 \mathrm{mg}$; de Wit et al., 2002), but not following a lower dose of amphetamine (10 mg, p.o.; de Wit et al., 2002), 150 and $300 \mathrm{mg}$ (p.o.) of the weak DA reuptake inhibitor bupropion (Acheson and de Wit, 2008), or the direct DA D2 agonist pramipexole $(0.25-0.50 \mathrm{mg}$, p.o.) (Hamidovic et al., 2008). Low to moderate doses of $d$ amphetamine (10, $20 \mathrm{mg}$, p.o.) also decreased effort discounting, meaning that participants were more willing to work hard to obtain large rewards (Wardle et al., 2011). In contrast to the above findings, administration of the immediate DA precursor, L-DOPA (150 mg, p.o.), has been reported to increase delay discounting (Pine et al., 2010), while a smaller dose (100 mg, p.o.) had no effect on a gambling task in which no feedback was provided (Symmonds et al., 2013). It has been proposed that DA might affect decision-making through its effects on learning from different forms of feedback (Collins and Frank, 2014). The absence of ongoing feedback during the gambling task might have prevented L-DOPA from exerting effects, as no learning was involved. It remains unclear whether the conflicting results reviewed above reflect lack of specificity of some of the compounds used, different paradigms affecting different aspects of performance, different behavioral effects from changes in phasic $v s$. tonic DA release, spurious findings in a still small literature, or something else.

In summary, the evidence is less consistent when it comes to impulsive choice. Animal studies point to dose-dependent effects, with small increases in DA improving performance on the DDT and larger doses leading to impairment. In humans, decreasing DA transmission increases impulsive, effort discounting, but the effects of DA augmenters and behavioral responses on other tasks are less consistent. In studies using gambling paradigms, poorer performance is seen following elevated DA transmission in rats and lowered DA in healthy human subjects. Additional research in humans is needed where different drugs and a wide range of doses are directly compared.

\section{SUMMARY AND CONCLUSIONS}

It was previously proposed that increased $v s$. decreased DA transmission might predispose individuals to premature responding $v s$. delay discounting (Leyton, 2007). Since then, the animal literature has grown, and the proposed demarcation stands up well. Studies in neurologically intact humans, though, remain scarce, and caution is warranted since the exact effects in humans and rodents are not always the same. For now, it remains unclear whether these differences reflect methodology (e.g., different drugs, routes of administration and tests), neurobiology (e.g., larger, more complex and more dense DA innervation of primate frontal cortex), or, more simply, the smaller number of studies in healthy human subjects.

\section{ACKNOWLEDGMENTS}

This work was supported by an operating grant from the Canadian Institutes of Health Research to Marco Leyton (MOP-36429). Valérie D'Amour-Horvat is a recipient of a student award from Fonds de la recherche du Québec-Santé (FRQ-S). We thank Yogita Chudasama for providing feedback on an earlier version of the manuscript.

\section{REFERENCES}

Aarts, E., Wallace, D. L., Dang, L. C., Jagust, W. J., Cools, R., and D'esposito, M. (2014). Dopamine and the cognitive downside of a promised bonus. Psychol. Sci. 25, 1003-1009. doi: 10.1177/0956797613517240

Acheson, A., and de Wit, H. (2008). Bupropion improves attention but does not affect impulsive behavior in healthy young adults. Exp. Clin. Psychopharmacol. 16, 113-123. doi: 10.1037/1064-1297.16.2.113

Ainslie, G. (1975). Specious reward: a behavioral theory of impulsiveness and impulse control. Psychol. Bull. 82, 463-496. doi: 10.1037/h00 76860

Amalric, M., Berhow, M., Polis, I., and Koob, G. F. (1993). Selective effects of low-dose D2 dopamine receptor antagonism in a reaction-time task in rats. Neuropsychopharmacology 8, 195-200. doi: 10.1038/npp.1993.21

Amalric, M., and Koob, G. (1987). Depletion of dopamine in the caudate nucleus but not in nucleus accumbens impairs reaction-time performance in rats. $J$. Neurosci. 7, 2129-2134.

American Psychiatric Association. (2013). The Diagnostic and Statistical Manual of Mental Disorders: DSM 5. Washington, D.C.: American Psychiatric Association.

Aron, A. R., Dowson, J. H., Sahakian, B. J., and Robbins, T. W. (2003). Methylphenidate improves response inhibition in adults with attentiondeficit/hyperactivity disorder. Biol. Psychiatry 54, 1465-1468. doi: 10 . 1016/s0006-3223(03)00609-7

Baarendse, P. J., and Vanderschuren, L. J. (2012). Dissociable effects of monoamine reuptake inhibitors on distinct forms of impulsive behavior in rats. Psychopharmacology (Berl) 219, 313-326. doi: 10.1007/s00213-0112576-x

Baarendse, P. J., Winstanley, C. A., and Vanderschuren, L. J. (2013). Simultaneous blockade of dopamine and noradrenaline reuptake promotes disadvantageous decision making in a rat gambling task. Psychopharmacology (Berl) 225, 719731. doi: $10.1007 / \mathrm{s} 00213-012-2857-z$ 
Bari, A., Eagle, D. M., Mar, A. C., Robinson, E. S. J., and Robbins, T. W. (2009). Dissociable effects of noradrenaline, dopamine and serotonin uptake blockade on stop task performance in rats. Psychopharmacology (Berl) 205, 273-283. doi: 10.1007/s00213-009-1537-0

Barrett, S. P., Pihl, R. O., Benkelfat, C., Brunelle, C., Young, S. N., and Leyton, M. (2008). The role of dopamine in alcohol self-administration in humans: individual differences. Eur. Neuropsychopharmacol. 18, 439-447. doi: 10.1016/j. euroneuro.2008.01.008

Baunez, C., Nieoullon, A., and Amalric, M. (1994). N-methyl-d-aspartate receptor blockade impairs behavioural performance of rats in a reaction time task: new evidence for glutamatergic-dopaminergic interactions in the striatum. Neuroscience 61, 521-531. doi: 10.1016/0306-4522(94) 90431-6

Baunez, C., Nieoullon, A., and Amalric, M. (1995). Dopamine and complex sensorimotor integration: further studies in a conditioned motor task in the rat. Neuroscience 65, 375-384. doi: 10.1016/0306-4522(94)00498-t

Bechara, A., Damasio, A. R., Damasio, H., and Anderson, S. W. (1994). Insensitivity to future consequences following damage to human prefrontal cortex. Cognition 50, 7-15. doi: 10.1016/0010-0277(94)90018-3

Bizot, J.-C. (1998). Effects of various drugs including organophosphorus compounds (OPC) and therapeutic compounds against OPC on DRL responding. Pharmacol. Biochem. Behav. 59, 1069-1080. doi: 10.1016/s0091-3057(97) 00519-4

Blokland, A., Sik, A., and Lieben, C. (2005). Evaluation of DOI, 8-OH-DPAT, eticlopride and amphetamine on impulsive responding in a reaction time task in rats. Behav. Pharmacol. 16, 93-100. doi: 10.1097/00008877-20050300000004

Brewer, J. A., and Potenza, M. N. (2008). The neurobiology and genetics of impulse control disorders: relationships to drug addictions. Biochem. Pharmacol. 75, 6375. doi: 10.1016/j.bcp.2007.06.043

Britton, K., and Koob, G. F. (1989). Effects of corticotropin releasing factor, desipramine and haloperidol on a DRL schedule of reinforcement. Pharmacol. Biochem. Behav. 32, 967-970. doi: 10.1016/0091-3057(89) 90067-1

Canon, J. G., and Lippa, A. S. (1977). Use of DRL in differentiating anxiolytic and neuroleptic properties of CNS drugs. Pharmacol. Biochem. Behav. 6, 591-593. doi: 10.1016/0091-3057(77)90122-8

Cardinal, R. N., Robbins, T. W., and Everitt, B. J. (2000). The effects of d-amphetamine, chlordiazepoxide, $\alpha$-flupenthixol and behavioural manipulations on choice of signalled and unsignalled delayed reinforcement in rats. Psychopharmacology (Berl) 152, 362-375. doi: 10.1007/s0021300 00536

Cawley, E. I., Park, S., aan het Rot, M., Sancton, K., Benkelfat, C., Young, S. N., et al. (2013). Dopamine and light: dissecting effects on mood and motivational states in women with subsyndromal seasonal affective disorder. J. Psychiatry Neurosci. 38, 388-397. doi: 10.1503/jpn.120181

Charrier, D., and Thiébot, M. H. (1996). Effects of psychotropic drugs on rat responding in an operant paradigm involving choice between delayed reinforcers. Pharmacol. Biochem. Behav. 54, 149-157. doi: 10.1016/0091-3057(95) 02114-0

Cheng, R., and Liao, R. (2007). Dopamine receptor antagonists reverse amphetamine-induced behavioral alteration on a differential reinforcement for low-rate (DRL) operant task in the rat. Chin. J. Physiol. 50, 77-88.

Cheng, R.-K., MacDonald, C. J., and Meck, W. H. (2006). Differential effects of cocaine and ketamine on time estimation: implications for neurobiological models of interval timing. Pharmacol. Biochem. Behav. 85, 114-122. doi: 10. 1016/j.pbb.2006.07.019

Cocker, P. J., Hosking, J. G., Benoit, J., and Winstanley, C. A. (2012). Sensitivity to cognitive effort mediates psychostimulant effects on a novel rodent cost/benefit decision-making task. Neuropsychopharmacology 37, 1825-1837. doi: $10.1038 /$ npp. 2012.30

Cole, B. J., and Robbins, T. W. (1987). Amphetamine impairs the discriminative performance of rats with dorsal noradrenergic bundle lesions on a 5-choice serial reaction time task: new evidence for central dopaminergic-noradrenergic interactions. Psychopharmacology (Berl) 91, 458-466. doi: 10.1007/bf00 216011

Collins, A. G., and Frank, M. J. (2014). Opponent actor learning (OpAL): modeling interactive effects of striatal dopamine on reinforcement learning and choice incentive. Psychol. Rev. 121, 337-366. doi: 10.1037/a0037015
Colzato, L. S., Jongkees, B. J., Sellaro, R., and Hommel, B. (2013). Working memory reloaded: tyrosine repletes updating in the N-back task. Front. Behav. Neurosci. 7:200. doi: 10.3389/fnbeh.2013.00200

Colzato, L. S., Jongkees, B. J., Sellaro, R., van den Wildenberg, W. P., and Hommel, B. (2014). Eating to stop: tyrosine supplementation enhances inhibitory control but not response execution. Neuropsychologia 62, 398-402. doi: 10.1016/j. neuropsychologia.2013.12.027

Costa, A., Riedel, M., Pogarell, O., Menzel-Zelnitschek, F., Schwarz, M., Reiser, M., et al. (2013). Methylphenidate effects on neural activity during response inhibition in healthy humans. Cereb. Cortex 23, 1179-1189. doi: 10. 1093/cercor/bhs 107

Dagher, A., and Robbins, T. W. (2009). Personality, addiction, dopamine: insights from Parkinson's disease. Neuron 61, 502-510. doi: 10.1016/j.neuron.2009. 01.031

Dalley, J. W., Mar, A. C., Economidou, D., and Robbins, T. W. (2008). Neurobehavioral mechanisms of impulsivity: fronto-striatal systems and functional neurochemistry. Pharmacol. Biochem. Behav. 90, 250-260. doi: 10.1016/j.pbb. 2007.12.021

Denk, F., Walton, M. E., Jennings, K. A., Sharp, T., Rushworth, M. F. S., and Bannerman, D. M. (2005). Differential involvement of serotonin and dopamine systems in cost-benefit decisions about delay or effort. Psychopharmacology (Berl) 179, 587-596. doi: 10.1007/s00213-004-2059-4

de Wit, H., Crean, J., and Richards, J. B. (2000). Effects of d-Amphetamine and ethanol on a measure of behavioral inhibition in humans. Behav. Neurosci. 114, 830-837. doi: 10.1037//0735-7044.114.4.830

de Wit, H., Enggasser, J., and Richards, J. B. (2002). Acute administration of damphetamine decreases impulsivity in healthy volunteers. Neuropsychopharmacology 27, 813-825. doi: 10.1016/s0893-133x(02)00343-3

Eagle, D. M., and Baunez, C. (2010). Is there an inhibitory-response-control system in the rat? Evidence from anatomical and pharmacological studies of behavioral inhibition. Neurosci. Biobehav. Rev. 34, 50-72. doi: 10.1016/j.neubiorev. 2009.07.003

Eagle, D. M., Lehmann, O., Theobald, D. E. H., Pena, Y., Zakaria, R., Ghosh, R., et al. (2009). Serotonin depletion impairs waiting but not stop-signal reaction time in rats: implications for theories of the role of 5-HT in behavioral inhibition. Neuropsychopharmacology 34, 1311-1321. doi: 10.1038/npp. 2008.202

Eagle, D. M., and Robbins, T. W. (2003). Inhibitory control in rats performing a stop-signal reaction-time task: effects of lesions of the medial striatum and d-amphetamine. Behav. Neurosci. 117, 1302-1317. doi: 10.1037/0735-7044.117. 6.1302

Eagle, D. M., Tufft, M. R. A., Goodchild, H. L., and Robbins, T. W. (2007). Differential effects of modafinil and methylphenidate on stop-signal reaction time task performance in the rat and interactions with the dopamine receptor antagonist cis-flupenthixol. Psychopharmacology (Berl) 192, 193-206. doi: 10. 1007/s00213-007-0701-7

Evenden, J., and Ryan, C. (1996). The pharmacology of impulsive behaviour in rats: the effects of drugs on response choice with varying delays of reinforcement. Psychopharmacology (Berl) 128, 161-170. doi: 10.1007/s002130050121

Fellows, L. K., and Farah, M. J. (2005). Different underlying impairments in decision-making following ventromedial and dorsolateral frontal lobe damage in humans. Cereb. Cortex 15, 58-63. doi: 10.1093/cercor/bhh108

Feola, T. W., de Wit, H., and Richards, J. B. (2000). Effects of d-Amphetamine and ethanol on a measure of behavioral inhibition in rats. Behav. Neurosci. 114, 838848. doi: 10.1037//0735-7044.114.4.838

Ferguson, S. A., Cada, A. M., Gray, E. P., and Paule, M. G. (2001). No alterations in the performance of two interval timing operant tasks after $\alpha$-difluoromethylornithine (DFMO)-induced cerebellar stunting. Behav. Brain Res. 126, 135-146. doi: 10.1016/s0166-4328(01)00259-5

Fernando, A. B., Economidou, D., Theobald, D. E., Zou, M.-F., Newman, A. H., Spoelder, M., et al. (2012). Modulation of high impulsivity and attentional performance in rats by selective direct and indirect dopaminergic and noradrenergic receptor agonists. Psychopharmacology (Berl) 219, 341-352. doi: 10. 1007/s00213-011-2408-z

Fillmore, M. T., Kelly, T. H., and Martin, C. A. (2005). Effects of $d$-amphetamine in human models of information processing and inhibitory control. Drug Alcohol Depend. 77, 151-159. doi: 10.1016/j.drugalcdep.2004.07.013

Fletcher, P., Rizos, Z., Noble, K., and Higgins, G. (2011). Impulsive action induced by amphetamine, cocaine and MK801 is reduced by $5-\mathrm{HT}$ (2C) receptor 
stimulation and 5-HT (2A) receptor blockade. Neuropharmacology 61, 468-477. doi: 10.1016/j.neuropharm.2011.02.025

Floresco, S., Tse, M., and Ghods-Sharifi, S. (2008). Dopaminergic and glutamatergic regulation of effort-and delay-based decision making. Neuropsychopharmacology 33, 1966-1979. doi: 10.1038/sj.npp.1301565

Frank, M. J. (2005). Dynamic dopamine modulation in the basal ganglia: a neurocomputational account of cognitive deficits in medicated and nonmedicated Parkinsonism. J. Cogn. Neurosci. 17, 51-72. doi: 10.1162/089892905 2880093

Gallagher, D. A., O'Sullivan, S. S., Evans, A. H., Lees, A. J., and Schrag, A. (2007), Pathological gambling in Parkinson's disease: risk factors and differences from dopamine dysregulation. An analysis of published case series. Mov. Disord. 22, 1757-1763. doi: 10.1002/mds.21611

Hamidovic, A., Kang, U. J., and de Wit, H. (2008). Effects of low to moderate acute doses of pramipexole on impulsivity and cognition in healthy volunteers. J. Clin. Psychopharmacol. 28, 45-51. doi: 10.1097/jcp.0b013e3181 $602 \mathrm{fab}$

Harrison, A. A., Everitt, B. J., and Robbins, T. W. (1997). Central 5-HT depletion enhances impulsive responding without affecting the accuracy of attentional performance: interactions with dopaminergic mechanisms. Psychopharmacology (Berl) 133, 329-342. doi: 10.1007/s002130050410

Helms, C. M., Reeves, J. M., and Mitchell, S. H. (2006). Impact of strain and d-amphetamine on impulsivity (delay discounting) in inbred mice. Psychopharmacology (Berl) 188, 144-151. doi: 10.1007/s00213-0060478-0

Howe, M. W., Tierney, P. L., Sandberg, S. G., Phillips, P. E., and Graybiel, A. M. (2013). Prolonged dopamine signalling in striatum signals proximity and value of distant rewards. Nature 500, 575-579. doi: 10.1038/nature 12475

Isles, A. R., Humby, T., and Wilkinson, L. S. (2003). Measuring impulsivity in mice using a novel operant delayed reinforcement task: effects of behavioural manipulations and d-amphetamine. Psychopharmacology (Berl) 170, 376-382. doi: 10.1007/s00213-003-1551-6

Kelm, M. K., and Boettiger, C. A. (2013). Effects of acute dopamine precusor depletion on immediate reward selection bias and working memory depend on catechol-o-methyltransferase genotype. J. Cogn. Neurosci. 25, 2061-2071. doi: 10.1162/jocn_a_00464

Koffarnus, M. N., Newman, A. H., Grundt, P., Rice, K. C., and Woods, J. H. (2011). Effects of selective dopaminergic compounds on a delay discounting task. Behav. Pharmacol. 22, 300-311. doi: 10.1097/FBP.0b013e3283473bcb

Leyton, M. (2007). Conditioned and sensitized responses to stimulant drugs in humans. Prog. Neuropsychopharmacol. Biol. Psychiatry 31, 1601-1613. doi: 10. 1016/j.pnpbp.2007.08.027

Leyton, M., aan het Rot, M., Booij, L., Baker, G. B., Young, S. N., and Benkelfat, C. (2007). Mood-elevating effects of d-amphetamine and incentive salience: the effect of acute dopamine precursor depletion. J. Psychiatry Neurosci. 32, 129136.

Leyton, M., and Vezina, P. (2014). Dopamine ups and downs in vulnerability to addictions: a neurodevelopmental model. Trends Pharmacol. Sci. 35, 268-276. doi: $10.1016 / j . t i p s .2014 .04 .002$

Liao, R., and Cheng, R. (2005). Acute effects of d-amphetamine on the differential reinforcement of low-rate (DRL) schedule behavior in the rat: comparison with selective dopamine receptor antagonists. Chin. J. Physiol. 48, $41-50$.

Logan, G. D., Cowan, W. B., and Davis, K. A. (1984). On the ability to inhibit simple and choice reaction time responses: a model and a method. J. Exp. Psychol. Hum. Percept. Perform. 10, 276-291. doi: 10.1037//0096-1523.10. 2.276

Loos, M., Staal, J., Schoffelmeer, A. N. M., Smit, A. B., Spijker, S., and Pattij, T. (2010). Inhibitory control and response latency differences between C57BL/6J and DBA/2J mice in a Go/No-Go and 5-choice serial reaction time task and strain-specific responsivity to amphetamine. Behav. Brain Res. 214, 216-224. doi: 10.1016/j.bbr.2010.05.027

Lythe, K., Anderson, I., Deakin, J., Elliott, R., and Strickland, P. (2005). Lack of behavioural effects after acute tyrosine depletion in healthy volunteers. J. Psychopharmacol. 19, 5-11. doi: 10.1177/0269881105048886

Ma, F., Falk, J. L., and Lau, C. E. (1999). Cocaine pharmacodynamics after intravenous and oral administration in rats: relation to pharmacokinetics.
Psychopharmacology (Berl) $\quad 144, \quad 323-332 . \quad$ doi: $10.1007 / 5002130$ 051014

Maguire, D. R., Henson, C., and France, C. P. (2014). Effects of amphetamine on delay discounting in rats depend upon the manner in which delay is varied. Neuropharmacology 87, 173-179. doi: 10.1016/j.neuropharm.2014.04. 012. [Epub ahead of print].

Marrow, L., Overton, P., and Clark, D. (1993). Disruption of conditioned reaction time performance by dopamine receptor antagonists in the rat. Behav. Pharmacol. 4, 15-28. doi: 10.1097/00008877-199302000-00002

McLean, A., Rubinsztein, J. S., Robbins, T. W., and Sahakian, B. J. (2004). The effects of tyrosine depletion in normal healthy volunteers: implications for unipolar depression. Psychopharmacology (Berl) 171, 286-297. doi: 10.1007/s00213-0031586-8

Milstein, J. A., Dalley, J. W., and Robbins, T. W. (2010). Methylphenidateinduced impulsivity: pharmacological antagonism by $\beta$-adrenoreceptor blockade. J. Psychopharmacol. 24, 309-321. doi: 10.1177/02698811080 98146

Mitchell, M. R., Vokes, C. M., Blankenship, A. L., Simon, N. W., and Setlow, B. (2011). Effects of acute administration of nicotine, amphetamine, diazepam, morphine and ethanol on risky decision-making in rats. Psychopharmacology (Berl) 218, 703-712. doi: 10.1007/s00213-0112363-8

Moore, T. J., Glenmullen, J., and Mattison, D. R. (2014). Reports of pathological gambling, hypersexuality and compulsive shopping associated with dopamine receptor agonist drugs. JAMA Intern. Med. doi: 10.1001/jamainternmed.2014. 5262. [Epub ahead of print].

Navarra, R., Graf, R., Huang, Y., Logue, S., Comery, T., Hughes, Z., et al. (2008). Effects of atomoxetine and methylphenidate on attention and impulsivity in the 5-choice serial reaction time test. Prog. Neuropsychopharmacol. Biol. Psychiatry 32, 34-41. doi: 10.1016/j.pnpbp.2007.06.017

Paine, T. A., and Olmstead, M. C. (2004). Cocaine disrupts both behavioural inhibition and conditional discrimination in rats. Psychopharmacology (Berl) 175, 443-450. doi: 10.1007/s00213-004-1845-3

Paterson, N. E., Wetzler, C., Hackett, A., and Hanania, T. (2012). Impulsive action and impulsive choice are mediated by distinct neuropharmacological substrates in rat. Int. J. Neuropsychopharmacol. 15, 1473-1487. doi: 10. $1017 /$ S1461145711001635

Pattij, T., Janssen, M. C., Vanderschuren, L. J., Schoffelmeer, A. N., and van Gaalen, M. M. (2007). Involvement of dopamine D1 and D2 receptors in the nucleus accumbens core and shell in inhibitory response control. Psychopharmacology (Berl) 191, 587-598. doi: 10.1007/s00213-0060533-x

Pine, A., Shiner, T., Seymour, B., and Dolan, R. J. (2010). Dopamine, time and impulsivity in humans. J. Neurosci. 30, 8888-8896. doi: 10.1523/JNEUROSCI. 6028-09.2010

Ramdani, C., Carbonnell, L., Vidal, F., Béranger, C., Dagher, A., and Hasbroucq, T. (2014). Dopamine precursors depletion impairs impulse control in healthy volunteers. Psychopharmacology (Berl) doi: 10.1007/s00213-014-3686-z. [Epub ahead of print].

Riba, J., Krämer, U. M., Heldmann, M., Richter, S., and Münte, T. F. (2008). Dopamine agonist increases risk taking but blunts reward-related brain activity. PLoS One 3:e2479. doi: 10.1371/journal.pone.0002479

Richards, J. B., Sabol, K. E., and Seiden, L. S. (1993). DRL interresponse-time distributions: quantification by peak deviation analysis. J. Exp. Anal. Behav. 60, 361-385. doi: 10.1901/jeab.1993.60-361

Robbins, T. (2002). The 5-choice serial reaction time task: behavioural pharmacology and functional neurochemistry. Psychopharmacology (Berl) 163, 362-380. doi: 10.1007/s00213-002-1154-7

Roberts, D., Gabriele, A., and Zimmer, B. A. (2013). Conflation of cocaine seeking and cocaine taking responses in IV self-administration experiments in rats: methodological and interpretational considerations. Neurosci. Biobehav. Rev. 37, 2026-2036. doi: 10.1016/j.neubiorev.2013. 04.017

Robinson, T. E., and Berridge, K. C. (2008). The incentive sensitization theory of addiction: some current issues. Philos. Trans. R. Soc. Lond. B Biol. Sci. 363, 31373146. doi: 10.1098/rstb.2008.0093

Robinson, E. S. J., Eagle, D. M., Economidou, D., Theobald, D. E. H., Mar, A. C., Murphy, E. R., et al. (2009). Behavioural characterisation of high 
impulsivity on the 5-choice serial reaction time task: specific deficits in 'waiting'versus 'stopping'. Behav. Brain Res. 196, 310-316. doi: 10.1016/j.bbr.2008. 09.021

Sabol, K. E., Richards, J. B., Layton, K., and Seiden, L. S. (1995). Amphetamine analogs have differential effects on DRL 36-s schedule performance. Psychopharmacology (Berl) 121, 57-65. doi: 10.1007/bf02245591

Salamone, J. D., Correa, M., Farrar, A. M., Nunes, E. J., and Pardo, M. (2009). Dopamine, behavioral economics and effort. Front. Behav. Neurosci. 3:13. doi: 10.3389/neuro.08.013.2009

Salamone, J. D., Steinpreis, R. E., McCullough, L. D., Smith, P., Grebel, D., and Mahan, K. (1991). Haloperidol and nucleus accumbens dopamine depletion suppress lever pressing for food but increase free food consumption in a novel food choice procedure. Psychopharmacology (Berl) 104, 515-521. doi: 10. 1007/bf02245659

Salamone, J. D., Wisniecki, A., Carlson, B. B., and Correa, M. (2001). Nucleus accumbens dopamine depletions make animals highly sensitive to high fixed ratio requirements but do not impair primary food reinforcement. Neuroscience 105, 863-870. doi: 10.1016/s0306-4522(01)0 0249-4

Sanger, D., Key, M., and Blackman, D. (1974). Differential effects of chlordiazepoxide and d-amphetamine on responding maintained by a DRL schedule of reinforcement. Psychopharmacologia 38, 159-171. doi: 10.1007/bf00 426110

Scarnà, A., McTavish, S. F. B., Cowen, P. J., Goodwin, G. M., and Rogers, R. D. (2005). The effects of a branched chain amino acid mixture supplemented with tryptophan on biochemical indices of neurotransmitter function and decisionmaking. Psychopharmacology (Berl) 179, 761-768. doi: 10.1007/s00213-0042105-2

Seiden, L. S., Andresen, J., and Mac Phail, R. C. (1979). Methylphenidate and $d$-amphetamine: effects and interactions with alphamethyltyrosine and tetrabenazine on DRL performance in rats. Pharmacol. Biochem. Behav. 10, 577-584. doi: 10.1016/0091-3057(79)90236-3

Sevy, S., Hassoun, Y., Bechara, A., Yechiam, E., Napolitano, B., Burdick, K., et al. (2006). Emotion-based decision-making in healthy subjects: short-term effects of reducing dopamine levels. Psychopharmacology (Berl) 188, 228-235. doi: 10. 1007/s00213-006-0450-z

Simon, N. W., Gilbert, R. J., Mayse, J. D., Bizon, J. L., and Setlow, B. (2009). Balancing risk and reward: a rat model of risky decision making. Neuropsychopharmacology 34, 2208-2217. doi: 10.1038/npp.2009.48

Simon, N. W., Montgomery, K. S., Beas, B. S., Mitchell, M. R., LaSarge, C. L., Mendez, I. A., et al. (2011). Dopaminergic modulation of risky decisionmaking. J. Neurosci. 31, 17460-17470. doi: 10.1523/JNEUROSCI.3772-11. 2011

Smith, A. D., Smith, D. L., Zigmond, M. J., Amalric, M., and Koob, G. F. (2000). Differential effects of dopamine receptor subtype blockade on performance of rats in a reaction-time paradigm. Psychopharmacology (Berl) 148, 355-360. doi: $10.1007 /$ s002130050063

Solanto, M. V., Abikoff, H., Sonuga-Barke, E., Schachar, R., Logan, G. D., Wigal, T., et al. (2001). The ecological validity of delay aversion and response inhibition as measures of impulsivity in $\mathrm{AD} / \mathrm{HD}$ : a supplement to the NIMH multimodal treatment study of AD/HD. J. Abnorm. Child Psychol. 29, 215-228. doi: 10. 1023/A:1010329714819

St Onge, J. R. S., Chiu, Y. C., and Floresco, S. B. (2010). Differential effects of dopaminergic manipulations on risky choice. Psychopharmacology (Berl) 211, 209-221. doi: 10.1007/s00213-010-1883-y

St Onge, J. R., and Floresco, S. B. (2009). Dopaminergic modulation of risk-based decision making. Neuropsychopharmacology 34, 681-697. doi: 10.1038/npp. 2008.121

Symmonds, M., Wright, N. D., Fagan, E., and Dolan, R. J. (2013). Assaying the effect of Levodopa on the evaluation of risk in healthy humans. PLoS One 8:e68177. doi: 10.1371/journal.pone.0068177

Tai, L.-H., Lee, A. M., Benavidez, N., Bonci, A., and Wilbrecht, L. (2012). Transient stimulation of distinct subpopulations of striatal neurons mimics changes in action value. Nat. Neurosci. 15, 1281-1289. doi: 10.1038/nn. 3188

Tanno, T., Maguire, D. R., Henson, C., and France, C. P. (2014). Effects of amphetamine and methylphenidate on delay discounting in rats: interactions with order of delay presentation. Psychopharmacology (Berl) 231, 85-95. doi: 10. 1007/s00213-013-3209-3
Tannock, R., Schachar, R. J., Carr, R. P., Chajczyk, D., and Logan, G. D. (1989). Effects of methylphenidate on inhibitory control in hyperactive children. $J$. Abnorm. Child Psychol. 17, 473-491. doi: 10.1007/bf00916508

Tremblay, A. M., Desmond, R. C., Poulos, C. X., and Zack, M. (2011). Haloperidol modifies instrumental aspects of slot machine gambling in pathological gamblers and healthy controls. Addict. Biol. 16, 467-484. doi: 10.1111/j.13691600.2010.00208.x

Trifilieff, P., and Martinez, D. (2014). Imaging addiction: D2 receptors and dopamine signaling in the striatum as biomarkers for impulsivity. Neuropharmacology 76, 498-509. doi: 10.1016/j.neuropharm.2013.06.031

van Enkhuizen, J., Geyer, M. A., and Young, J. W. (2013). Differential effects of dopamine transporter inhibitors in the rodent Iowa gambling task. Psychopharmacology (Berl) 225, 661-674. doi: 10.1007/s00213-012-2854-2

van Gaalen, M. M., Brueggeman, R. J., Bronius, P. F., Schoffelmeer, A. N., and Vanderschuren, L. J. (2006b). Behavioral disinhibition requires dopamine receptor activation. Psychopharmacology (Berl) 187, 73-85. doi: 10.1007/s00213-0060396-1

van Gaalen, M. M., Unger, L., Jongen-Rêlo, A.-L., Schoemaker, H., and Gross, G. (2009). Amphetamine decreases behavioral inhibition by stimulation of dopamine D2, but not D3, receptors. Behav. Pharmacol. 20, 484-491. doi: 10. 1097/FBP.0b013e3283305e3b

van Gaalen, M. M., van Koten, R., Schoffelmeer, A. N., and Vanderschuren, L. J. (2006a). Critical involvement of dopaminergic neurotransmission in impulsive decision making. Biol. Psychiatry 60, 66-73. doi: 10.1016/j.biopsych.2005. 06.005

van Hest, A., van Drimmelen, M., and Olivier, B. (1992). Flesinoxan shows antidepressant activity in a DRL 72-s screen. Psychopharmacology (Berl) 107, 474-479. doi: 10.1007/bf02245258

Venugopalan, V. V., Casey, K. F., O’Hara, C., O’Loughlin, J., Benkelfat, C., Fellows, L. K., et al. (2011). Acute phenylalanine/tyrosine depletion reduces motivation to smoke cigarettes across stages of addiction. Neuropsychopharmacology 36, 2469-2476. doi: 10.1038/npp.2011.135

Wade, T. R., de Wit, H., and Richards, J. B. (2000). Effects of dopaminergic drugs on delayed reward as a measure of impulsive behavior in rats. Psychopharmacology (Berl) 150, 90-101. doi: 10.1007/s002130000402

Wang, Q., Simpao, A., Sun, L., Falk, J., and Lau, C. (2001). Contribution of the active metabolite, norcocaine, to cocaine's effects after intravenous and oral administration in rats: pharmacodynamics. Psychopharmacology (Berl) 153, 341-352. doi: 10.1007/s002130000568

Wardle, M. C., Treadway, M. T., Mayo, L. M., Zald, D. H., and de Wit, H. (2011). Amping up effort: effects of d-amphetamine on human effort-based decisionmaking. J. Neurosci. 31, 16597-16602. doi: 10.1523/JNEUROSCI.4387-11. 2011

Waters, K. A., Burnham, K. E., O'connor, D., Dawson, G. R., and Dias, R. (2005). Assessment of modafinil on attentional processes in a five-choice serial reaction time test in the rat. J. Psychopharmacol. 19, 149-158. doi: 10. 1177/0269881105048995

Wenger, G. R., and Wright, D. W. (1990). Behavioral effects of cocaine and its interaction with $d$-amphetamine and morphine in rats. Pharmacol. Biochem. Behav. 35, 595-600. doi: 10.1016/0091-3057(90)90296-t

Wiley, J. L., Compton, A. D., and Golden, K. M. (2000). Separation of drug effects on timing and behavioral inhibition by increased stimulus control. Exp. Clin. Psychopharmacol. 8, 451-461. doi: 10.1037//1064-1297.8. 4.451

Winstanley, C. A. (2011). The utility of rat models of impulsivity in developing pharmacotherapies for impulse control disorders. Br. J. Pharmacol. 164, 13011321. doi: 10.1111/j.1476-5381.2011.01323.x

Winstanley, C. A., Dalley, J. W., Theobald, D. E. H., and Robbins, T. W. (2003). Global 5-HT depletion attenuates the ability of amphetamine to decrease impulsive choice on a delay-discounting task in rats. Psychopharmacology (Berl) 170, 320-331. doi: 10.1007/s00213-003-1546-3

Winstanley, C. A., Eagle, D. M., and Robbins, T. W. (2006). Behavioral models of impulsivity in relation to ADHD: translation between clinical and preclinical studies. Clin. Psychol. Rev. 26, 379-395. doi: 10.1016/j.cpr.2006. 01.001

Winstanley, C. A., LaPlant, Q., Theobald, D. E. H., Green, T. A., Bachtell, R. K., Perrotti, L. I., et al. (2007). $\triangle$ FosB induction in orbitofrontal cortex mediates tolerance to cocaine-induced cognitive dysfunction. J. Neurosci. 27, 1049710507. doi: 10.1523/jneurosci.2566-07.2007 
Woolverton, W., Kandel, D., and Schuster, C. R. (1978). Effects of repeated administration of cocaine on schedule-controlled behavior of rats. Pharmacol. Biochem. Behav. 9, 327-337. doi: 10.1016/0091-3057(78)90293-9

Zack, M., and Poulos, C. X. (2007). A D2 antagonist enhances the rewarding and priming effects of a gambling episode in pathological gamblers. Neuropsychopharmacology 32, 1678-1686. doi: 10.1038/sj.npp.1301295

Zeeb, F. D., Robbins, T. W., and Winstanley, C. A. (2009). Serotonergic and dopaminergic modulation of gambling behavior as assessed using a novel rat gambling task. Neuropsychopharmacology 34, 2329-2343. doi: 10.1038/npp. 2009.62

Conflict of Interest Statement: The authors declare that the research was conducted in the absence of any commercial or financial relationships that could be construed as a potential conflict of interest.
Received: 14 July 2014; accepted: 26 November 2014; published online: 23 December 2014.

Citation: D'Amour-Horvat $V$ and Leyton $M$ (2014) Impulsive actions and choices in laboratory animals and humans: effects of high vs. low dopamine states produced by systemic treatments given to neurologically intact subjects. Front. Behav. Neurosci. 8:432. doi: $10.3389 /$ fnbeh.2014.00432

This article was submitted to the journal Frontiers in Behavioral Neuroscience.

Copyright (c) 2014 D'Amour-Horvat and Leyton. This is an open-access article distributed under the terms of the Creative Commons Attribution License (CC BY). The use, distribution and reproduction in other forums is permitted, provided the original author(s) or licensor are credited and that the original publication in this journal is cited, in accordance with accepted academic practice. No use, distribution or reproduction is permitted which does not comply with these terms. 